\title{
A produção de artigos de ensino de Física no estado do Acre: motivações e avanços ${ }^{+*}$
}

Eloi Benicio de Melo Junior ${ }^{1}$

Doutorando em Física

Centro Brasileiro de Pesquisas Físicas

Rio de Janeiro - RJ

Marcelo Castanheira da Silva ${ }^{1}$

Universidade Federal do Acre

Rio Branco - AC

\section{Resumo}

Este trabalho apresenta uma revisão sistemática, no periodo de 2005 a 2019, da produção de artigos de Ensino de Física no Acre. A revisão sistemática permite uma revisão de literatura com rigor científico. A produção científica dessa área no estado iniciou no ano de 2015 e, desde então, os temas mais pesquisados em Ensino de Física no Acre são: atividades lúdicas (30\%), formação docente (25\%), Tecnologias da Informação e Comunicação - TICs - (25\%), atividades experimentais (15\%) e avaliação (5\%). Dos 20 trabalhos selecionados, 60\% foram produzidos por licenciandos e $40 \%$ por discentes dos mestrados profissionais existentes na UFAC, o Mestrado Nacional Profissional em Ensino de Física (MNPEF Polo-59) e o Mestrado Profissional em Ensino de Ciências e Matemática (MPECIM). Notou-se que o PIBID, residência pedagógica e os mestrados profissionais contribuem para a mudança de atitude dos docentes e licenciados. Além disso, ficou evidente a contribuição da Universidade Pública para a produção cientifica.

Palavras-chave: Revisão Sistemática; Acre; Ensino de Física; Produção Cientifica.

\footnotetext{
${ }^{+}$The production of Physics teaching papers in the state of Acre: motivations and advances

${ }^{*}$ Recebido: 8 de junho de 2020. Aceito: 16 de abril de 2021.

${ }^{1}$ E-mails: eloibmj@cbpf.br; marcelo.silva@ufac.br
} 


\begin{abstract}
This paper presents a systematic review, in the period from 2005 to 2019, of the production of Physics Teaching articles in Acre. The systematic review allows for a literature review with scientific rigor. The scientific production of this area in the state started in 2015 and, since then, the most researched subjects in Physics Teaching in Acre are: recreational activities (30\%), teacher training (25\%), Information and Communication Technologies - ICTs - (25\%), experimental activities (15\%) and evaluation (5\%). Of the 20 selected works, 60\% were produced by undergraduate students and $40 \%$ by students of the professional master's degrees at UFAC, the National Professional Master's in Physics Teaching (MNPEF Polo-59) and the Professional Master's in Science and Mathematics Teaching (MPECIM). It was noted that PIBID, pedagogical residency and professional master's degrees contribute to the change in attitude of teachers and graduates. In addition, the contribution of the Public University to scientific production was evident.
\end{abstract}

Keywords: Systematic Review; Acre; Physics Education; Scientific Production.

\title{
I. Introdução
}

A produção científica do Brasil em 2005 representava cerca de 1,4\% e 0,1\% da ciência e tecnologia mundial, respectivamente (ALBUQUERQUE et al., 2005). Hoje, apesar do crescimento de $30 \%$ da produção brasileira, o país ainda ocupa a $13^{\mathrm{a}}$ posição no ranking de produção mundial (USP, 2019). Outro ponto importante da produção científica nacional é a concentração dessas pesquisas em determinadas regiões como a Sudeste. Albuquerque et al. (2009) defendem uma melhor distribuição regional das pesquisas científicas, contudo para isso é preciso investimentos para fomentar a pesquisa e a ciência em regiões menos favorecidas (SIDONE; HADDAD; MENA-CHALCO, 2016). Até o momento de concepção deste artigo, o sistema de concessão de bolsas de mestrado e doutorado do Conselho Nacional de Desenvolvimento Científico e Tecnológico (CNPq) segue a portaria $\mathrm{n}^{\mathrm{o}} 1.122$, de 19 de março de 2020 (BRASIL, 2020a), que estabelece áreas prioritárias, nas quais não estão inclusas as ciências humanas. A Coordenação de Aperfeiçoamento de Pessoal de Nível Superior (CAPES), por meio da portaria $\mathrm{n}^{\mathrm{o}}$ 34, de 9 de março de 2020 (BRASIL, 2020b), estabelece um novo modelo de concessão de bolsas, priorizando os cursos mais bem avaliados, que em geral estão concentrados nas regiões Sul e Sudeste. 
Assim como no âmbito nacional, é importante preocupar-se com pesquisa na esfera regional e local, especificamente acerca do Ensino de Ciências. Pereira e Silveira (2019) analisaram a produção acadêmica da região Norte do Brasil, a partir da ata do XI Encontro Nacional de Pesquisa em Educação em Ciências (ENPEC, 2017), realizado em julho de 2017, e constataram que a contribuição do estado do Acre para essa produção é de apenas $8 \%$. Em nível local, porém, não havia, até a realização deste estudo, um trabalho referente à produção do Ensino de Física no Acre, um dos motivos que levaram a execução dessa pesquisa.

O Acre está localizado na Amazônia Ocidental e possui somente uma universidade federal, a Universidade Federal do Acre (UFAC), com federalização em 1974. O curso de Licenciatura em Física foi criado no ano de 2005. A instituição conta, entre outros, com um Mestrado Profissional de Ensino de Ciências e Matemática (MPECIM), criado em 2012 com o parecer CNE/CES n n $^{\circ} 424 / 2015$, sob a iniciativa de professores dos cursos de Licenciatura em Ciências Biológicas, Física, Química, Matemática e Pedagogia. Conta, também, com um polo do Mestrado Nacional Profissional de Ensino de Física (MNPEF Polo-59) credenciado em 2015. O MNPEF, programa de nível nacional, foi criado em 2013 com iniciativa da Sociedade Brasileira de Física (SBF).

A primeira turma do MPECIM ingressou em 2013. As vagas desse mestrado são divididas entre as duas linhas de pesquisa: Ensino de Ciências e Ensino de Matemática. A distribuição dessas vagas segue o critério de disponibilidade de cada professor para orientação dentro de cada uma das linhas, o que pode causar variação na oferta de vagas entre editais. A primeira linha (Ensino de Ciências) abrange Biologia, Física e Química, consequentemente envolvendo mais docentes. O público-alvo desse programa são professores da Educação Básica de ensino em exercício que atuem em Ensino de Ciências ou de Matemática. O objetivo é aprimorar a formação continuada dos docentes, a partir de atividades de pesquisa aplicada e o desenvolvimento da prática pedagógica. A seleção é anual e conta com um edital local.

O MNPEF no Acre teve a primeira turma em 2016; desde então, o programa disponibiliza em torno de dez vagas para o polo 59 voltadas, preferencialmente, aos professores de Física da Educação Básica que estejam exercendo a docência. O objetivo do programa é capacitar uma grande quantidade de professores da rede básica de ensino em relação ao domínio dos conteúdos da Física e técnicas para o ensino e aplicação em sala de aula. A seleção é anual e conta com um edital local, porém é acrescida de um edital nacional. O MPECIM também tem uma seleção anual, porém existe somente um edital local.

O curso de Licenciatura em Física da UFAC está presente somente no campus Rio Branco (campus sede da UFAC) e dispunha de 50 vagas de ingresso anual. A partir desse ano (2020), houve ampliação para 55 vagas, sendo 35 vagas para o curso de Licenciatura e 20 vagas para o Bacharelado (com opção de obter formação complementar em Geofísica). A licenciatura dedica-se à formação do profissional docente para atuar na educação formal nos 
anos finais do Ensino Fundamental e no Ensino Médio e proporcionar saberes básicos para seguir formação acadêmica em nível de mestrado e doutorado.

Entendendo a importância de estudar a produção científica, sobretudo em um local onde ainda não havia relatos de estudos dessa natureza, foi realizado um estudo para compreender as motivações e analisar a quantidade de publicações científicas (artigos) no período de 2005 a 2019. Esse período foi escolhido pelo fato de o curso de licenciatura ter iniciado em 2005, onde foi possível analisar o papel de cada parte do tripé (Licenciatura, MNPEF e MPECIM) nessa produção.

\section{Passos Metodológicos}

Essa pesquisa caracteriza-se como pesquisa bibliográfica, uma vez que "a pesquisa bibliográfica é desenvolvida com base em material já elaborado, constituído principalmente de livros e artigos científicos" (GIL, 2002, p. 44). Para Gil (2002), a principal vantagem desse tipo de pesquisa é a garantia que tem o investigador da cobertura de uma faixa de fenômenos maior do que ele poderia pesquisar de forma direta.

Para melhor aproveitar a gama de materiais que se pretendia levantar e extrair deles todas as informações pertinentes, optou-se pela revisão sistemática de literatura, que "é uma forma de pesquisa que utiliza como fonte de dados a literatura sobre determinado tema" (SAMPAIO; MANCINI, 2007, p. 84). Galvão, Sawada e Trevizan (2004) apresentam como essa pesquisa pode ser realizada em sete fases:

$1^{\mathrm{a}}$. Construção do protocolo: garante que a revisão seja desenvolvida com o mesmo rigor de uma pesquisa científica;

$2^{\mathrm{a}}$. Definição da pergunta: a pergunta guia a revisão, pois define os estudos escolhidos e estratégias adotadas. A pergunta escolhida nesse trabalho foi: "Quais as motivações e periodicidade das publicações em Ensino de Física no estado do Acre?".

$3^{\text {a }}$. Busca dos estudos: selecionar as bases eletrônicas de dados, considerar quais são os periódicos pertinentes e buscar em mais de uma base de dados;

4 . Seleção dos estudos: a seleção é guiada pelos critérios determinados no protocolo;

5. Avaliação crítica: todos os estudos selecionados são avaliados com rigor metodológico;

6 . Coleta de dados: deve incluir informações sobre o público envolvido, intervenções, resultados e o local onde foi realizada a pesquisa;

$7^{\mathrm{a}}$. Síntese dos dados: sintetizar os dados provenientes de cada estudo. 
$\mathrm{Na} 1^{\mathrm{a}}$ fase, definimos a estratégia de busca dos estudos (executada na $3^{\mathrm{a}}$ fase), como seriam classificados e avaliados (executada na $5^{\text {a }}$ fase) e como seria feita a coleta e síntese dos dados (executada na $6^{\mathrm{a}}$ e $7^{\mathrm{a}}$ fase).

Não foi fácil utilizar as fontes de dados comumente escolhidas em trabalhos dessa natureza (Ensino de Física no Acre) como a Scientific Electronic Library Online (SciELO) e o Portal de Periódicos da CAPES (PPC), que usa como base, além do SciELO, o Directory of Open Access Journals (DOAJ) entre outros, dado que nem todos os manuscritos estão publicados em revistas indexadas em todas essas fontes. Ainda assim, seguindo o estabelecido na terceira fase da pesquisa sistemática, realizamos buscas nessas bases, utilizando os descritores Ensino; Física e Acre, refinando a busca no período de 2005 a 2019. No SciELO e DOAJ, a pesquisa retornou 6 artigos e no Portal de Periódicos da CAPES, 76 artigos.

Além da busca nas bases de dados citadas acima, realizamos uma busca diretamente no currículo Lattes dos docentes do curso de licenciatura em Física, da Universidade Federal do Acre (UFAC). O uso dessa fonte de dados, além cumprir com a terceira fase da pesquisa sistemática, visou a garantir que os manuscritos produzidos pelos docentes e discentes do curso de licenciatura fossem computados. Durante a pesquisa notou-se que grande parte da produção realizada pelos docentes da rede básica estadual de ensino concentra-se em anais de eventos, que não serão considerados nessa pesquisa, pois estão em formas de resumo sem um aprofundamento metodológico, teórico e das discussões dos resultados, de maneira que não é possível executar as fases 5 e 6 da revisão sistemática.

Para melhor selecionar os resultados das buscas que serão analisados e cumprir com a $4^{\text {a }}$ fase da revisão sistemática, utilizamos os critérios: (1) período da publicação de 2005 a 2019, (2) área da pesquisa (Ensino de Física), (3) localidade (Estado do Acre), (4) não ser publicado em anais de eventos, (5) estar disponível na íntegra e (6) publicado em periódico com avaliação por pares. Durante a seleção, foram considerados título, resumo e periódico onde o artigo está publicado. Após isso, seguindo o estabelecido na $5^{a}$ fase da revisão sistemática, os trabalhos foram lidos na íntegra e classificados segundo seus objetivos e natureza, ou linha do trabalho, que pode ser: formação docente, métodos de ensino e aprendizagem, tecnologia no Ensino de Física, entre outras. A Fig. 1 apresenta o fluxograma do levantamento bibliográfico.

Como a primeira turma do MPECIM ingressou em 2014, a escolha na busca dos artigos, no período de 2005 a 2019, permitiu verificar se antes da implementação do programa havia artigos de Ensino de Física publicados em periódicos revisados por pares, no entanto isso não ocorreu entre os anos de 2005 a 2014.

Dessbesel, Silva e Shimazaki (2018) apresentam um exemplo, que será seguido neste trabalho, de como usar a revisão sistemática para extrair dados importantes da literatura em estudo. As seções seguintes tratam de corresponder ao exigido nas fases 6 e 7 da revisão sistemática. 


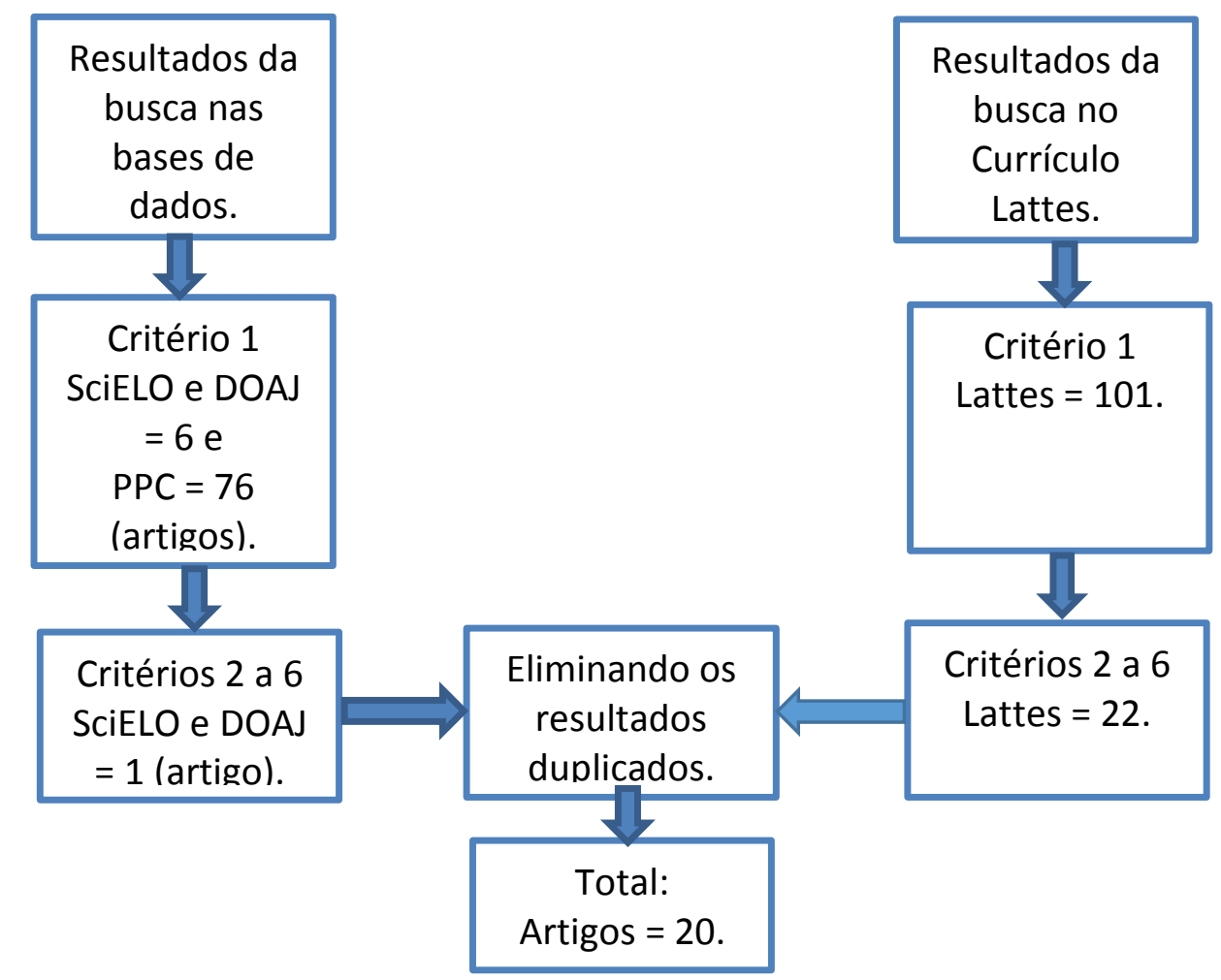

Fig. 1 - Fluxograma da revisão bibliográfica. Siglas utilizadas: SciELO - Scientific Eletronic Library Online; DOAJ - Directory of Open Access Journals; PPC - Portal de Periódicos da CAPES. Os números após o sinal de igualdade representam a quantidade de artigos encontrados em cada base de dados. Fonte: elaborado pelos autores.

\section{Resultados e discussões}

A Fig. 2 exibe as porcentagens de trabalhos por natureza, a partir do levantamento, cujas temáticas pesquisadas em Ensino de Física são: Avaliação, Atividades Lúdicas, Tecnologias da Informação e Comunicação (TICs), Atividade Experimental e Formação Docente.

Da Fig. 2 nota-se que as atividades lúdicas obtêm o maior índice de artigos publicados (30\%). Após as leituras desses trabalhos, observou-se que o maior interesse em publicações dessa natureza se dá devido a dois motivos: o primeiro por buscarem uma alternativa às atividades experimentais; o segundo foi fruto do trabalho desenvolvido pelos discentes do curso de licenciatura em Física da UFAC, envolvidos no Programa Institucional de Bolsas de Iniciação à Docência (PIBID) e Residência Pedagógica, que executaram projetos dessa natureza nas escolas.

O PIBID é um programa de apoio à formação docente bem estabelecido com implementação em 2007 e "é uma ação que visa proporcionar aos discentes na primeira metade do curso de licenciatura uma aproximação prática com o cotidiano das escolas públicas de educação básica e com o contexto em que elas estão inseridas" (CAPES, 2018a). 


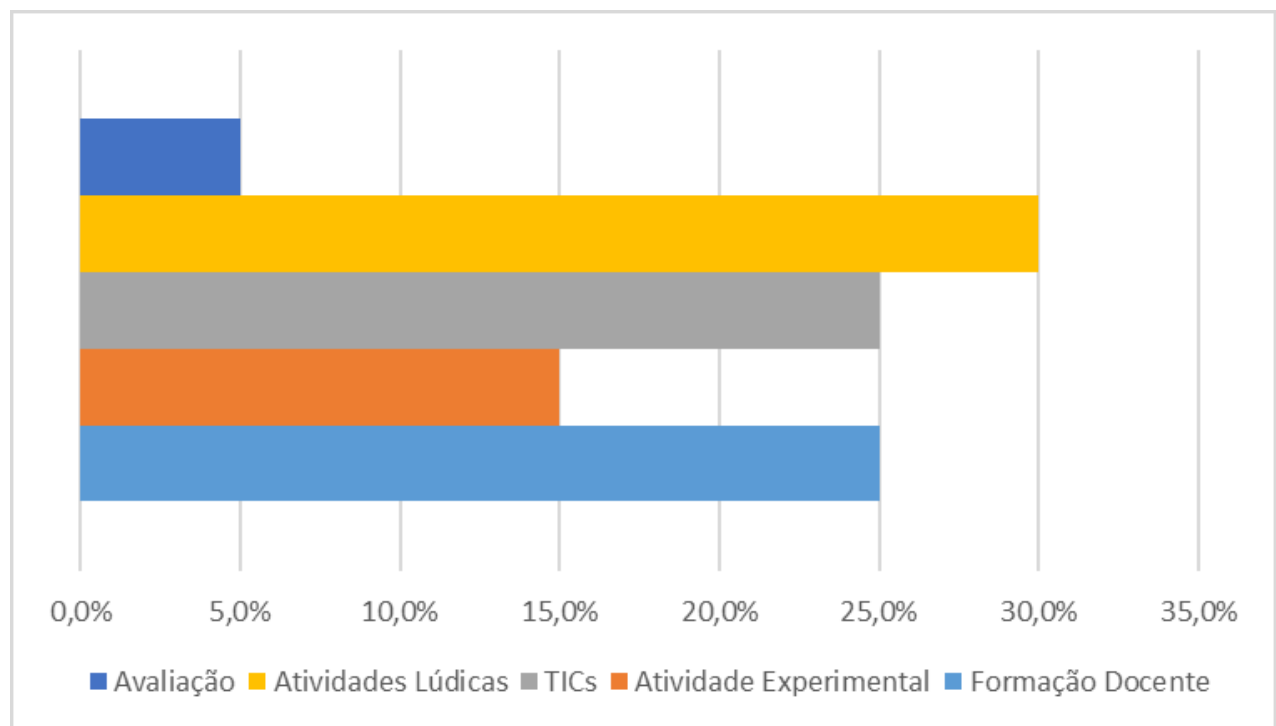

Fig. 2 - Porcentagem de trabalhos por natureza. Fonte: elaborado pelos autores.

A Residência Pedagógica é um projeto mais recente, implementado em 2018, similar ao PIBID, contudo voltado aos licenciandos da segunda metade da graduação com o objetivo de induzir o aperfeiçoamento da formação prática nos cursos de licenciatura, promovendo a imersão do licenciando na escola de educação básica (CAPES, 2018b).

A formação docente apresentou $25 \%$ das publicações, isso ocorreu por meio dos trabalhos desenvolvidos por alunos do PIBID, docentes e discentes do MPECIM e MNPEF. Além desses, os artigos referentes às TICs (25\%) seguem essa mesma lógica; trabalhos dessa natureza são atrativos a mestrandos desses programas, dado que esses podem ser trabalhados juntamente com outras linhas de pesquisa, como formação docente, o que possibilita a aplicação de seu produto em diversos ambientes, seja na graduação ou no ensino básico. Esse movimento de trabalho conjunto é observado, também, internacionalmente (TRAN et al., 2018).

Uma pesquisa simples e quantitativa foi realizada em três periódicos, utilizando os descritores TIC, Tecnologias Digitais, Tecnologias Digitais da Informação e Comunicação, Dispositivos Móveis e Tecnologias da Informação e Comunicação. A pesquisa retornou os seguintes resultados: Revista Brasileira de Ensino de Física (2 artigos), Revista do Professor de Física (1 artigo), Ciência e Educação (7 artigos) e Caderno Brasileiro de Ensino de Física (8 artigos, sendo 1, revisão bibliográfica). A maior frequência de publicação desses trabalhos inicia a partir de 2016, dessa forma, pode-se ter uma noção que é crescente o interesse por publicações dessa linha nos últimos anos e que possa ter influenciado na escolha do tema de pesquisa dos alunos desses programas, assim como motivar a publicação de artigos advindos dessas dissertações.

Dos artigos selecionados referentes às atividades experimentais (15\%), somente um está ligado a alunos participantes do PIBID e é a segunda menor temática abordada nos 
trabalhos selecionados. Isso aponta que a formação de professores no curso de licenciatura da UFAC e a capacitação, a partir dos mestrados profissionais, estão adotando preferencialmente o uso de atividades lúdicas, formação docente e uso de TIC. Essa situação mostra que a formação docente está buscando alternativas e proporcionando aos licenciandos e mestrandos diferentes experiências, métodos e abordagens para o Ensino de Física. Para reforçar este argumento foi destacado o trabalho de Araújo e Santos (2018) que faz uso de uma atividade lúdica (Jogo das Grandezas) em duas disciplinas (Instrumentação de Ensino de Física I e Instrumentação de Ensino de Física V) voltadas para o aperfeiçoamento da prática docente e elaboração de novos materiais didáticos; esse jogo foi desenvolvido e aplicado por um licenciando.

Os resultados exibidos na Fig. 2 chamam atenção para outro fato: a pesquisa em avaliação tem o menor índice de publicação (5,0\%), especificamente somente um trabalho (MELO JUNIOR; SOUZA; SILVA, 2019), com uma peculiaridade, o artigo apresenta uma análise dos resultados obtidos por alunos da rede básica de ensino do estado do Acre na Olimpíada Brasileira de Física das Escolas Públicas (OBFEP), no período de 2015 a 2018, levando em consideração as situações de vulnerabilidade socioeconômica dos participantes.

O quadro 1 apresenta os 20 trabalhos selecionados, os objetivos e os conteúdos abordados. Uma identificação numérica (Id) foi criada para facilitar a localização dos trabalhos ao longo do artigo.

Quadro 1 - Artigos, objetivos e natureza dos trabalhos selecionados. Id é a identificação numérica do trabalho. Fonte: elaborado pelos autores.

\begin{tabular}{|c|c|c|c|}
\hline Id & Artigos & Objetivos & Conteúdo abordado \\
\hline 1 & $\begin{array}{c}\text { Amorim } \text { et } \\
\text { al. (2018) }\end{array}$ & $\begin{array}{c}\text { Facilitar o processo de ensino e } \\
\text { aprendizagem utilizando recursos lúdicos } \\
\text { elaborados por licenciandos. }\end{array}$ & $\begin{array}{c}\text { Termologia e calor: calor sensível, } \\
\text { calor latente; processos de } \\
\text { transmissão de calor: condução, } \\
\text { convecção e irradiação. }\end{array}$ \\
\hline 2 & $\begin{array}{c}\text { Araújo e } \\
\text { Santos } \\
(2018)\end{array}$ & $\begin{array}{c}\text { Utilizar o "Jogo das Grandezas" como } \\
\text { ferramenta de avaliação dos conhecimentos } \\
\text { teóricos em Físia e proporcionar aos } \\
\text { jogadores correlação entre teoria e cotidiano. }\end{array}$ & $\begin{array}{c}\text { Mecânica, ondulatória, física } \\
\text { moderna, eletromagnetismo, } \\
\text { termodinâmica e óptica. }\end{array}$ \\
\hline 3 & $\begin{array}{c}\text { Costa e } \\
\text { Santos } \\
(2017)\end{array}$ & $\begin{array}{c}\text { Investigar os conteúdos estudados pelos } \\
\text { ingressantes na licenciatura durante o Ensino } \\
\text { Médio }\end{array}$ & $\begin{array}{c}\text { Formação de professores; } \\
\text { Parâmetros Curriculares Nacionais. }\end{array}$ \\
\hline 4 & $\begin{array}{c}\text { Duarte e } \\
\text { Nemer } \\
(2019)\end{array}$ & $\begin{array}{c}\text { Relatar a experiência didática para o Ensino } \\
\text { de Física com o uso de tecnologias móveis } \\
\text { por estudantes de uma escola do Ensino } \\
\text { Médio. }\end{array}$ & Eletricidade e magnetismo. \\
\hline 5 & $\begin{array}{c}\text { Esteves e } \\
\text { Silva } \\
(2019)\end{array}$ & $\begin{array}{c}\text { Analisar a eficácia do uso das TIC, disposta } \\
\text { em diversos meios e sua contribuição para o } \\
\text { processo cognitivo dos alunos de Ensino } \\
\text { Médio. }\end{array}$ & $\begin{array}{c}\text { Levantamento bibliográfico; TICs } \\
\text { e processo de aprendizagem. }\end{array}$ \\
\hline 6 & $\begin{array}{c}\text { Gomes, } \\
\text { Carmo e }\end{array}$ & $\begin{array}{c}\text { Apresentar um relato de experiência com o } \\
\text { uso de música como recurso didático para o }\end{array}$ & $\begin{array}{c}\text { Impulso e quantidade de } \\
\text { movimento. }\end{array}$ \\
\hline
\end{tabular}




\begin{tabular}{|c|c|c|c|}
\hline & $\begin{array}{l}\text { Santos } \\
(2018)\end{array}$ & ensino de física. & \\
\hline 7 & $\begin{array}{l}\text { Hadad, } \\
\text { Melo } \\
\text { Junior e } \\
\text { Silva } \\
(2018)\end{array}$ & $\begin{array}{l}\text { Verificar a eficácia de uma sequência de } \\
\text { didática com uso de simulação } \\
\text { computacional em uma turma de } \\
\text { Licenciatura em Física da UFAC. }\end{array}$ & Eletricidade; circuitos; capacitor. \\
\hline 8 & $\begin{array}{l}\text { Melo } \\
\text { Junior e } \\
\text { Silva } \\
(2017)\end{array}$ & $\begin{array}{c}\text { Comparar os métodos de ensino tradicional } \\
\text { e cognitivista utilizando atividades } \\
\text { experimentais em uma Escola de Ensino } \\
\text { Médio. }\end{array}$ & $\begin{array}{l}\text { Processos de eletrização: atrito, } \\
\text { indução e contato. }\end{array}$ \\
\hline 9 & $\begin{array}{l}\text { Melo } \\
\text { Junior, } \\
\text { Souza e } \\
\text { Silva } \\
\text { (2019) }\end{array}$ & $\begin{array}{l}\text { Analisar os resultados da OBFEP no Acre } \\
\text { entre } 2015 \text { e } 2018 \text { considerando as } \\
\text { condições de vulnerabilidade } \\
\text { socioeconômica. }\end{array}$ & $\begin{array}{c}\text { Avaliação; relação entre } \\
\text { aprendizagem e situação de } \\
\text { vulnerabilidade socioeconômica. }\end{array}$ \\
\hline 10 & $\begin{array}{l}\text { Moreira et } \\
\text { al. (2019) }\end{array}$ & $\begin{array}{l}\text { Apresentar uma proposta de ensino, baseada } \\
\text { em uma gincana de jogo da velha e relatar os } \\
\text { resultados do estudo. }\end{array}$ & $\begin{array}{l}\text { Leis de Newton; trabalho e } \\
\text { energia. }\end{array}$ \\
\hline 11 & $\begin{array}{l}\text { Moura, } \\
\text { Melo } \\
\text { Junior e } \\
\text { Silva } \\
(2019) \\
\end{array}$ & $\begin{array}{l}\text { Usar a teoria de modelos mentais para } \\
\text { interpretar as explicações dos alunos sobre o } \\
\text { conceito de movimento. }\end{array}$ & Cinemática. \\
\hline 12 & $\begin{array}{l}\text { Oliveira et } \\
\text { al. }(2015)\end{array}$ & $\begin{array}{l}\text { Contribuir para a diversidade e melhoria do } \\
\text { material didático utilizado em turmas de } \\
\text { Educação de Jovens e Adultos (EJA) no } \\
\text { estado do Acre; }\end{array}$ & $\begin{array}{l}\text { Óptica; eletrostática; } \\
\text { eletrodinâmica e magnetismo. }\end{array}$ \\
\hline 13 & $\begin{array}{l}\text { Santos, } \\
\text { Pinheiro e } \\
\text { Rocha } \\
(2019)\end{array}$ & $\begin{array}{c}\text { Investigar o ponto de vista dos alunos e } \\
\text { comunidade externa à UFAC quanto as } \\
\text { atividades apresentadas no I Congresso de } \\
\text { Física do Acre; }\end{array}$ & $\begin{array}{l}\text { Formação de professores; } \\
\text { divulgação científica. }\end{array}$ \\
\hline 14 & $\begin{array}{l}\text { Santos, } \\
\text { Gomes e } \\
\text { Souza } \\
(2018)\end{array}$ & $\begin{array}{l}\text { Compartilhar uma experiência sobre ensino } \\
\text { de física executada, com o uso de } \\
\text { experimentos e mnemônicos como recurso } \\
\text { pedagógico facilitador para o processo } \\
\text { ensino-aprendizagem. }\end{array}$ & $\begin{array}{l}\text { Associação de resistores e } \\
\text { capacitores. }\end{array}$ \\
\hline 15 & $\begin{array}{l}\text { Santos et } \\
\text { al. }(2019)\end{array}$ & $\begin{array}{c}\text { Utilizar Tecnologias da Informação e } \\
\text { Comunicação (TICs) em uma Sequência de } \\
\text { Ensino Investigativa (SEI) para estudo da } \\
\text { Lei de Hooke em uma Escola de Ensino } \\
\text { Médio. }\end{array}$ & Lei de Hooke. \\
\hline 16 & $\begin{array}{l}\text { Santos et } \\
\text { al. }(2018)\end{array}$ & $\begin{array}{l}\text { Investigar as contribuições e limitações do } \\
\text { PIBID no curso de Licenciatura em Física da } \\
\text { UFAC à formação inicial dos bolsistas } \\
\text { participantes. }\end{array}$ & Formação docente; PIBID. \\
\hline 17 & $\begin{array}{l}\text { Souza, } \\
\text { Santos e } \\
\text { Ghidini } \\
(2019)\end{array}$ & $\begin{array}{l}\text { Apresentar os resultados iniciais do projeto } \\
\text { de Extensão "Ciências na Escola: } \\
\text { experimentação e teoria" }\end{array}$ & $\begin{array}{l}\text { Prática pedagógica; oficinas; } \\
\text { formação docente. }\end{array}$ \\
\hline 18 & $\begin{array}{l}\text { Rego, Silva } \\
\text { e Peralta } \\
(2018) \\
\end{array}$ & $\begin{array}{c}\text { Utilizando Tecnologias da Informação e } \\
\text { Comunicação (TICs) em procedimentos } \\
\text { didáticos dos conteúdos iniciais da }\end{array}$ & $\begin{array}{c}\text { História da eletricidade; processos } \\
\text { de eletrização. }\end{array}$ \\
\hline
\end{tabular}




\begin{tabular}{|c|c|c|c|}
\hline 19 & $\begin{array}{c}\text { Reis } \text { et al. } \\
(2018)\end{array}$ & $\begin{array}{c}\text { Propor um jogo em uma sequência didática } \\
\text { para o ensino de termometria. }\end{array}$ & Termometria; temperatura; calor \\
\hline 20 & $\begin{array}{c}\text { Rocha, } \\
\text { Santos e } \\
\begin{array}{c}\text { Pinheiro } \\
(2019)\end{array}\end{array}$ & $\begin{array}{c}\text { Investigar a opinião, quanto à satisfação, dos } \\
\text { estudantes da licenciatura em Física em } \\
\text { relação ao curso. }\end{array}$ & $\begin{array}{c}\text { Investigação qualitativa; formação } \\
\text { docente. }\end{array}$ \\
\hline
\end{tabular}

A Fig. 3 apresenta os trabalhos expostos no quadro 1, numa estrutura de conjuntos, com a identificação numérica Id (que é a identificação numérica dos artigos utilizada nos quadros 1 e 2) e os organiza por natureza e/ou temáticas. Alguns trabalhos, além da sua natureza principal, apresentavam resultados e metodologias que foram ou têm possibilidade de serem executados juntamente a trabalhos de outra natureza, conforme podem ser vistos nas regiões de interseção da Fig. 3. É importante destacar que, para o gráfico da Fig. 2, foi considerado como critério o objetivo principal do trabalho e a predominância da natureza presente no manuscrito.

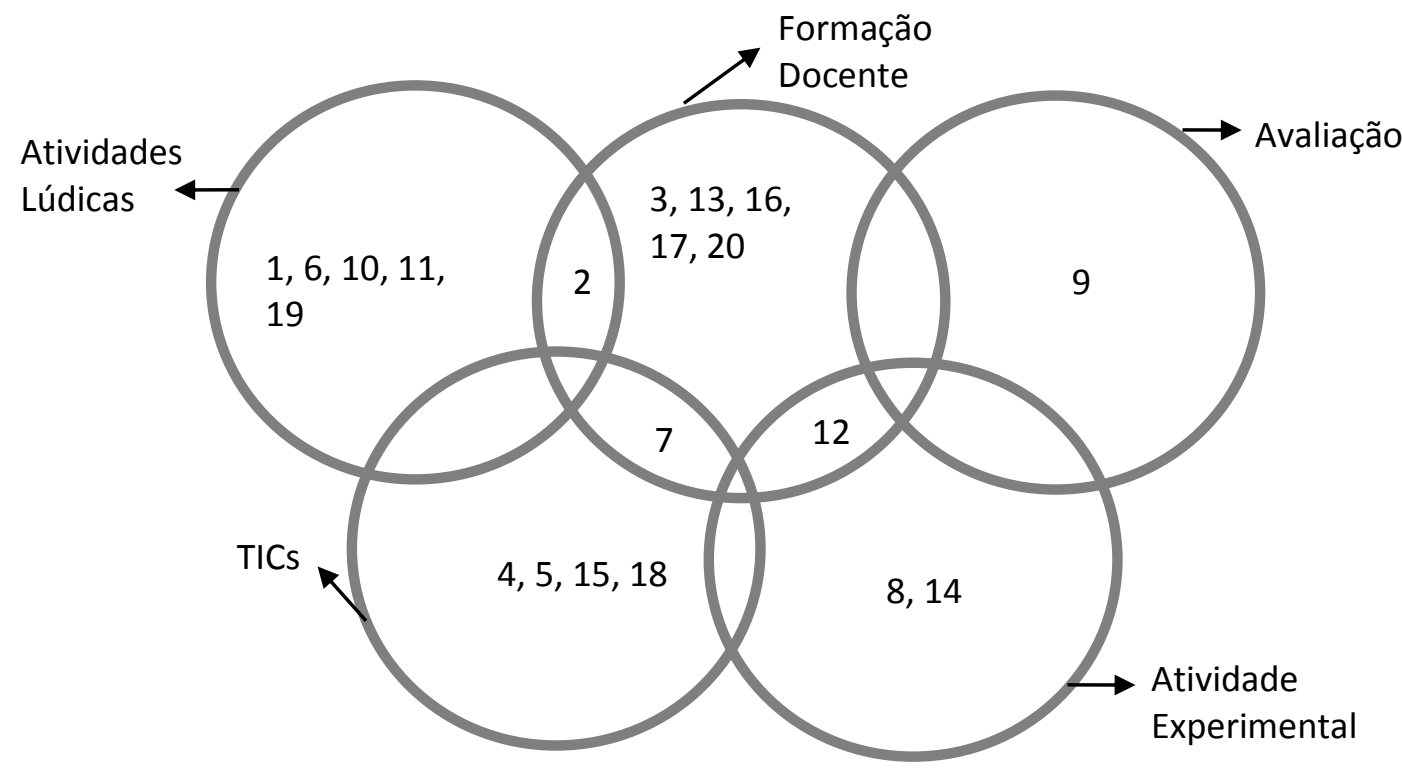

Fig. 3 - Organização em conjunto da natureza/linha dos trabalhos. Os números dentro dos círculos são as identificações numéricas dos artigos (Id). Os artigos que estão na interseção têm características de duas temáticas. Fonte: elaborado pelos autores.

Estima-se, com base nas leituras, que os manuscritos selecionados e organizados no quadro 1 atingiram cerca de 631 alunos entre o $1^{\circ}$ e o $4^{\circ}$ ano do Ensino Médio da rede básica estadual e federal, sendo 8 escolas estaduais e 2 campi do Instituto Federal do Acre (IFAC), em Sena Madureira e em Cruzeiro do Sul. Atingiram, também, por volta de 209 alunos da licenciatura em Física como público alvo ou como agentes da pesquisa, sendo membros do 
PIBID, Residência Pedagógica e Grupo de Pesquisa e Extensão em Ensino de Ciência (GPEC).

Em relação às metodologias de pesquisa adotadas nos artigos selecionados, $80 \%$ fazem uso da abordagem qualitativa, que "preocupa-se, portanto, com aspectos da realidade que não podem ser quantificados, centrando-se na compreensão e explicação da dinâmica das relações sociais" (SILVEIRA; CÓRDOVA, 2009).

O quadro 2 sintetiza os estudos selecionados e os procedimentos metodológicos de pesquisa e de ensino empregados nos trabalhos. Grande parte dos estudos não utilizam referenciais teóricos na análise dos dados, o que pode significar uma lacuna nesses artigos. Não há uma diversidade grande entre os instrumentos de coleta, sendo que $75 \%$ fazem uso de questionário. Na seção metodológica, nem todos os manuscritos indicaram a instituição onde estava ocorrendo a pesquisa, contudo em todos os artigos em que o público-alvo era do Ensino Médio, as instituições pertenciam à esfera estadual de ensino. Um trabalho não tinha uma metodologia de pesquisa bem definida, especificamente o trabalho de identificação numérica (Id) igual a 4.

Quadro 2 - Passos metodológicos dos artigos selecionados. Id é identificação numérica do trabalho. Abreviações empregadas: E. M. - Ensino Médio; EJA - Educação de Jovens e Adultos. Fonte: elaborado pelos autores. *Esta pesquisa versa sobre o levantamento de dados e análise dos mesmos, não sendo utilizada nenhuma metodologia de ensino.

\begin{tabular}{|c|c|c|c|c|c|c|}
\hline Id & Sujeitos & Local & $\begin{array}{l}\text { Metodo- } \\
\text { logia } \\
\text { Utilizada } \\
\text { (Pesquisa) }\end{array}$ & $\begin{array}{c}\text { Metodologia } \\
\text { Utilizada } \\
\text { (Ensino) }\end{array}$ & $\begin{array}{l}\text { Instrumento } \\
\text { de Coleta }\end{array}$ & $\begin{array}{l}\text { Análise dos } \\
\text { Dados }\end{array}$ \\
\hline 1 & $\begin{array}{l}\text { Alunos do } 3^{\circ} \\
\text { ano do E.M. }\end{array}$ & $\begin{array}{l}\text { Instituição } \\
\text { não } \\
\text { mencionada. } \\
\text { Rio Branco - } \\
\text { AC. }\end{array}$ & Qualitativa & $\begin{array}{l}\text { Inicialmente } \\
\text { tradicional, } \\
\text { seguida por } \\
\text { uma } \\
\text { estratégia de } \\
\text { ensino ativa }\end{array}$ & $\begin{array}{l}\text { Questionário e } \\
\text { observações } \\
\text { feitas pelos } \\
\text { pesquisadores. }\end{array}$ & $\begin{array}{l}\text { Análise das } \\
\text { respostas dos } \\
\text { alunos ao } \\
\text { questionário e } \\
\text { observação do } \\
\text { desempenho e } \\
\text { dedicação } \\
\text { durante a } \\
\text { atividade. }\end{array}$ \\
\hline 2 & $\begin{array}{l}\text { Alunos da } \\
\text { graduação } \\
\text { do } 1^{\circ} \text { e } 8^{\circ} \\
\text { período do } \\
\text { curso de } \\
\text { licenciatura } \\
\text { em Física - } \\
\text { UFAC }\end{array}$ & $\begin{array}{l}\text { Universidade } \\
\text { Federal do } \\
\text { Acre. Rio } \\
\text { Branco- } \\
\text { AC. }\end{array}$ & Qualitativa. & Gamificação & $\begin{array}{l}\text { Questionário e } \\
\text { observações } \\
\text { feitas pelos } \\
\text { pesquisadores. }\end{array}$ & $\begin{array}{c}\text { Observação da } \\
\text { participação e } \\
\text { comportament } \\
\text { o dos } \\
\text { participantes e } \\
\text { análise das } \\
\text { respostas do } \\
\text { questionário. }\end{array}$ \\
\hline
\end{tabular}




\begin{tabular}{|c|c|c|c|c|c|c|}
\hline 3 & $\begin{array}{l}\text { Discentes do } \\
1^{\circ} \text { período } \\
\text { do curso de } \\
\text { licenciatura } \\
\text { em Física - } \\
\text { UFAC } \\
\end{array}$ & $\begin{array}{c}\text { Universidade } \\
\text { Federal do } \\
\text { Acre. Rio } \\
\text { Branco - } \\
\text { AC. }\end{array}$ & $\begin{array}{l}\text { Qualitativa } \\
\text { e levanta- } \\
\text { mento }\end{array}$ & $\begin{array}{c}\text { Não } \\
\text { aplicável*. }\end{array}$ & Questionário & $\begin{array}{c}\text { Análise crítica } \\
\text { e investigativa } \\
\text { das respostas } \\
\text { do } \\
\text { questionário. }\end{array}$ \\
\hline 4 & $\begin{array}{l}\text { Alunos do } 3^{\circ} \\
\text { ano do E.M. }\end{array}$ & $\begin{array}{l}\text { Instituição } \\
\text { não } \\
\text { mencionada. } \\
\text { Rio Branco - } \\
\text { AC. }\end{array}$ & $\begin{array}{c}\text { Não } \\
\text { definida }\end{array}$ & $\begin{array}{l}\text { Metodologia } \\
\text { ativa. }\end{array}$ & Observação & $\begin{array}{l}\text { Interpretação } \\
\text { das } \\
\text { observações } \\
\text { realizadas pela } \\
\text { pesquisadora. }\end{array}$ \\
\hline 5 & $\begin{array}{c}\text { Discentes do } \\
\text { E.M. }\end{array}$ & Acre & $\begin{array}{l}\text { Revisão } \\
\text { bibliográ- } \\
\text { fica }\end{array}$ & $\begin{array}{c}\text { Não } \\
\text { aplicável*. }\end{array}$ & $\begin{array}{c}\text { Banco de } \\
\text { dados }\end{array}$ & $\begin{array}{c}\text { Análise da } \\
\text { bibliografia } \\
\text { levantada }\end{array}$ \\
\hline 6 & $\begin{array}{l}\text { Alunos do } 1^{\circ} \\
\text { ano do E.M. }\end{array}$ & $\begin{array}{c}\text { Escola Dr. } \\
\text { Santiago } \\
\text { Dantas. Rio } \\
\text { Branco - AC } \\
\text { (Zona Rural). }\end{array}$ & Qualitativa & $\begin{array}{l}\text { Metodologia } \\
\text { ativa. }\end{array}$ & $\begin{array}{l}\text { Observação e } \\
\text { questionário. }\end{array}$ & $\begin{array}{c}\text { Comparação } \\
\text { das análises da } \\
\text { observação e } \\
\text { resultados do } \\
\text { questionário. }\end{array}$ \\
\hline 7 & $\begin{array}{c}\text { Discentes do } \\
4^{\circ} \text { período da } \\
\text { licenciatura } \\
\text { em Física e } \\
\text { Engenharia } \\
\text { Civil - } \\
\text { UFAC. }\end{array}$ & $\begin{array}{l}\text { Universidade } \\
\text { Federal do } \\
\text { Acre. Rio } \\
\text { Branco - } \\
\text { AC. }\end{array}$ & Qualitativa & $\begin{array}{l}\text { Combinação } \\
\text { do método } \\
\text { tradicional e } \\
\text { ativo. }\end{array}$ & Questionário & $\begin{array}{c}\text { Análise das } \\
\text { respostas } \\
\text { dadas no } \\
\text { questionário. }\end{array}$ \\
\hline 8 & $\begin{array}{l}\text { Alunos do } 3^{\circ} \\
\text { ano do E.M. }\end{array}$ & $\begin{array}{c}\text { Escola } \\
\text { Glória Perez. } \\
\text { Rio Branco - } \\
\text { AC }\end{array}$ & Qualitativa & $\begin{array}{l}\text { Mescla dos } \\
\text { métodos } \\
\text { tradicional e } \\
\text { ativo. }\end{array}$ & $\begin{array}{l}\text { Questionário e } \\
\text { observações }\end{array}$ & $\begin{array}{c}\text { Análise das } \\
\text { observações e } \\
\text { questionário } \\
\text { sob o } \\
\text { referencial de } \\
\text { Vygotsky e } \\
\text { Ausubel. }\end{array}$ \\
\hline 9 & $\begin{array}{c}\text { Participantes } \\
\text { da OBFEP. }\end{array}$ & Acre & $\begin{array}{l}\text { Qualitativa } \\
\mathrm{e} \\
\text { quantitativa }\end{array}$ & $\begin{array}{c}\text { Não } \\
\text { aplicável*. }\end{array}$ & $\begin{array}{l}\text { Resultados da } \\
\text { OBFEP entre } \\
2015 \text { e } 2018 .\end{array}$ & $\begin{array}{c}\text { Análise dos } \\
\text { resultados sob } \\
\text { a ótica de } \\
\text { Rezende e } \\
\text { Ostermann } \\
\text { (2012) }\end{array}$ \\
\hline 10 & $\begin{array}{l}\text { Alunos do } 1^{\circ} \\
\text { ano do E.M. }\end{array}$ & $\begin{array}{c}\text { Instituição } \\
\text { não } \\
\text { mencionada. } \\
\text { Rio Branco - } \\
\text { AC. } \\
\end{array}$ & Qualitativa & $\begin{array}{l}\text { Associação } \\
\text { do método } \\
\text { tradicional } \\
\text { com o ativo } \\
\text { fazendo uso }\end{array}$ & $\begin{array}{l}\text { Observação de } \\
\text { trabalho em } \\
\text { grupo e } \\
\text { questionário. }\end{array}$ & $\begin{array}{l}\text { Utilizou-se a } \\
\text { perspectiva de } \\
\text { interação } \\
\text { social } \\
\text { discutida por }\end{array}$ \\
\hline
\end{tabular}




\begin{tabular}{|c|c|c|c|c|c|c|}
\hline & & & & de jogos. & & Duran. \\
\hline 11 & $\begin{array}{l}\text { Alunos do } 1^{\circ} \\
\text { ano do E.M. }\end{array}$ & $\begin{array}{c}\text { IFAC - } \\
\text { Campus } \\
\text { Sena } \\
\text { Madureira. } \\
\text { Sena } \\
\text { Madureira - } \\
\text { AC. }\end{array}$ & $\begin{array}{l}\text { Qualitativa } \\
\text { e revisão } \\
\text { bibliográ- } \\
\text { fica }\end{array}$ & $\begin{array}{l}\text { Uso de } \\
\text { jogos, } \\
\text { tradicional e } \\
\quad \text { ativa. }\end{array}$ & $\begin{array}{c}\text { Entrevista, } \\
\text { questionário e } \\
\text { observação. }\end{array}$ & $\begin{array}{l}\text { Fez-se uso do } \\
\text { conceito de } \\
\text { modelos } \\
\text { mentais de } \\
\text { Johnson-Laird. }\end{array}$ \\
\hline 12 & $\begin{array}{l}\text { Estudantes } \\
\text { do EJA/AC. }\end{array}$ & $\begin{array}{c}\text { Escolas: } \\
\text { Raimundo } \\
\text { Gomes de } \\
\text { Oliveira, } \\
\text { Paulo Freire } \\
\text { e Padre } \\
\text { Diogo Feijó. } \\
\text { Rio Branco - } \\
\text { AC. } \\
\end{array}$ & Qualitativa & $\begin{array}{l}\text { Tradicional, } \\
\text { seguida da } \\
\text { ativa fazendo } \\
\text { uso da } \\
\text { aprendiza- } \\
\text { gem } \\
\text { significativa. }\end{array}$ & Questionário. & $\begin{array}{l}\text { Análise das } \\
\text { respostas do } \\
\text { questionário, } \\
\text { tendo como } \\
\text { referencial o } \\
\text { conceito de } \\
\text { aprendizagem } \\
\text { significativa } \\
\text { de Ausubel. }\end{array}$ \\
\hline 13 & $\begin{array}{c}\text { Discentes da } \\
\text { licenciatura } \\
\text { em Física - } \\
\text { UFAC. }\end{array}$ & $\begin{array}{l}\text { Universidade } \\
\text { Federal do } \\
\text { Acre. Rio } \\
\text { Branco - } \\
\text { AC. }\end{array}$ & $\begin{array}{c}\text { Descritiva e } \\
\text { levanta- } \\
\text { mento }\end{array}$ & $\begin{array}{c}\text { Não } \\
\text { aplicável*. }\end{array}$ & Questionário. & $\begin{array}{l}\text { Análise das } \\
\text { respostas do } \\
\text { questionário. }\end{array}$ \\
\hline 14 & $\begin{array}{l}\text { Alunos do } 3^{\circ} \\
\text { ano do E.M. }\end{array}$ & $\begin{array}{c}\text { Escola Dr. } \\
\text { Santiago } \\
\text { Dantas. Rio } \\
\text { Branco - } \\
\text { AC. }\end{array}$ & $\begin{array}{l}\text { Qualitativa } \\
\mathrm{e} \\
\text { quantitativa }\end{array}$ & $\begin{array}{l}\text { Cooperação } \\
\text { entre } \\
\text { tradicional e } \\
\text { ativa. }\end{array}$ & $\begin{array}{l}\text { Questionário } \\
\text { opinário. }\end{array}$ & $\begin{array}{l}\text { Análise das } \\
\text { respostas do } \\
\text { questionário. }\end{array}$ \\
\hline 15 & $\begin{array}{l}\text { Discentes do } \\
1^{\mathrm{o}} \text { ano do } \\
\text { E.M. }\end{array}$ & $\begin{array}{c}\text { IFAC - } \\
\text { Campus } \\
\text { Cruzeiro do } \\
\text { Sul. Cruzeiro } \\
\text { do Sul - AC. }\end{array}$ & $\begin{array}{l}\text { Qualitativa, } \\
\text { levanta- } \\
\text { mento e } \\
\text { quantitativa }\end{array}$ & $\begin{array}{c}\text { Ativa e } \\
\text { tradicional. }\end{array}$ & Questionário. & $\begin{array}{l}\text { Análise das } \\
\text { respostas do } \\
\text { questionário. }\end{array}$ \\
\hline 16 & $\begin{array}{l}\text { Participantes } \\
\text { do PIBID } \\
\text { Licenciatura } \\
\text { em Física. }\end{array}$ & $\begin{array}{l}\text { Universidade } \\
\text { Federal do } \\
\text { Acre. Rio } \\
\text { Branco - } \\
\text { AC. }\end{array}$ & $\begin{array}{l}\text { Qualitativa } \\
\text { e levanta- } \\
\text { mento }\end{array}$ & $\begin{array}{c}\text { Não } \\
\text { aplicável*. }\end{array}$ & $\begin{array}{l}\text { Questionário } \\
\text { semiestrutu- } \\
\text { rado. }\end{array}$ & $\begin{array}{l}\text { Análise das } \\
\text { respostas do } \\
\text { questionário. }\end{array}$ \\
\hline 17 & $\begin{array}{l}\text { Participantes } \\
\text { do projeto de } \\
\text { extensão } \\
\text { "Ciências na } \\
\text { Escola: } \\
\text { experimenta } \\
\text { ção e teoria" }\end{array}$ & $\begin{array}{c}\text { Universidade } \\
\text { Federal do } \\
\text { Acre. Rio } \\
\text { Branco - } \\
\text { AC. }\end{array}$ & Qualitativa & Ativa. & $\begin{array}{c}\text { Observação } \\
\text { das atividades } \\
\text { executadas } \\
\text { pelos } \\
\text { participantes. }\end{array}$ & $\begin{array}{c}\text { Levantamento } \\
\text { da literatura } \\
\text { produzida } \\
\text { pelos } \\
\text { participantes e } \\
\text { desenvolvimen } \\
\text { to didático } \\
\end{array}$ \\
\hline
\end{tabular}




\begin{tabular}{|c|c|c|c|c|c|c|}
\hline & & & & & & $\begin{array}{l}\text { durante o } \\
\text { projeto. }\end{array}$ \\
\hline 18 & $\begin{array}{l}\text { Alunos do } 3^{\circ} \\
\text { ano do E.M. }\end{array}$ & $\begin{array}{c}\text { Instituição } \\
\text { não } \\
\text { mencionada. } \\
\text { Rio Branco - } \\
\text { AC. } \\
\end{array}$ & $\begin{array}{l}\text { Qualitativa } \\
\text { e descritiva }\end{array}$ & $\begin{array}{l}\text { Tradicional } \\
\text { em } \\
\text { colaboração } \\
\text { com ativa. }\end{array}$ & $\begin{array}{c}\text { Formulário em } \\
\text { plataforma } \\
\text { digital. }\end{array}$ & $\begin{array}{l}\text { Análise das } \\
\text { respostas do } \\
\text { formulário. }\end{array}$ \\
\hline 19 & $\begin{array}{l}\text { Discentes do } \\
3^{\circ} \text { ano do } \\
\text { E.M. }\end{array}$ & $\begin{array}{c}\text { Instituição } \\
\text { não } \\
\text { mencionada. } \\
\text { Rio Branco - } \\
\text { AC. }\end{array}$ & $\begin{array}{l}\text { Quantita- } \\
\text { tiva e } \\
\text { qualitativa }\end{array}$ & $\begin{array}{l}\text { Tradicional } \\
\text { seguida da } \\
\text { metodologia } \\
\text { ativa e uso } \\
\text { de jogos. }\end{array}$ & $\begin{array}{l}\text { Observação e } \\
\text { questionário. }\end{array}$ & $\begin{array}{c}\text { Comparação } \\
\text { dos resultados } \\
\text { das } \\
\text { observações } \\
\text { com os } \\
\text { resultados do } \\
\text { questionário. }\end{array}$ \\
\hline 20 & $\begin{array}{l}\text { Alunos do } \\
\text { curso de } \\
\text { Licenciatura } \\
\text { em Física - } \\
\text { UFAC. }\end{array}$ & $\begin{array}{l}\text { Universidade } \\
\text { Federal do } \\
\text { Acre. Rio } \\
\text { Branco - } \\
\text { AC. }\end{array}$ & $\begin{array}{l}\text { Investiga- } \\
\text { tiva e } \\
\text { qualitativa }\end{array}$ & $\begin{array}{c}\text { Não } \\
\text { aplicável*. }\end{array}$ & Questionário. & $\begin{array}{l}\text { Análise das } \\
\text { respostas do } \\
\text { questionário. }\end{array}$ \\
\hline
\end{tabular}

Gamificação é uso de design de games em cenários fora dos games, com o intuito de motivar, prender a atenção e elevar a atividade do usuário. Entendemos que a gamificação pode ser utilizada como uma estratégia de ensino ativa, mas não necessariamente é uma metodologia ativa. Para ser considerada metodologia de ensino ativa, o professor, como um mediador, a partir de regras explícitas, deve desafiar e estimular os alunos a realizarem as suas tarefas ou missões. Nos trabalhos analisados que fizeram uso da gamificação, identificamos que essa estratégia pode ser considerada como uma metodologia de ensino ativa, seguindo os critérios apontados por Silva, Sales e Castro (2019). No quadro 2, entretanto, optamos por deixar explícita essa estratégia.

Percebe-se, ainda, que parte dos artigos utiliza a metodologia de ensino tradicional seguida ou em colaboração com a metodologia ativa. Esse fato é devido as metodologias dos trabalhos, em especial as de Id 1, 7, 8, 10, 12 e 18, em seus passos metodológicos iniciarem com uma revisão ou apresentação dos conteúdos com uma aula expositiva de maneira tradicional. Concluímos isso a partir da leitura dos artigos, onde identificamos que o momento expositivo continha elementos de uma metodologia tradicional, onde os discentes apenas escutavam e respondiam as perguntas do professor. Esses elementos são classificados por Libâneo (1994) como um conjunto que compõe a metodologia tradicional.

A Fig. 4 exibe a publicação entre 2005 e 2019 em forma gráfica. Até 2015, não havia artigos publicados em periódicos revisados por pares, a primeira publicação, portanto, ocorreu somente 10 anos após a abertura do curso de Licenciatura em Física da Universidade Federal do Acre. É notório que houve uma expressiva crescente nas publicações nos anos de 2018 e 2019. Esse resultado (Fig. 4) responde a segunda parte da pergunta "Quais as motivações e 
periodicidade das publicações em Ensino de Física no estado do Acre?”, definida na segunda fase da revisão sistemática.

Além do mais, a Fig. 4 chama atenção para o impacto positivo dos programas PIBID, Residência Pedagógica e os mestrados profissionais, pois como citado anteriormente as publicações em Ensino de Física iniciaram após a implementação do PIBID e Residência Pedagógica e nota-se desta figura que esses programas contribuíram para o crescimento das publicações científicas. Fica claro que esses programas proporcionaram uma mudança de atitude referente a pesquisa e publicação dos discentes e docentes da Licenciatura em Física da UFAC. Dessa forma, reforçamos que o investimento nesses programas tem um retorno valioso para a comunidade científica e principalmente para a sociedade em geral, pois com a prática da pesquisa os futuros professores sairão com uma formação ainda mais sólida, com um conhecimento variado entre as teorias e métodos e com a prática da investigação, tudo isso poderá ser sentido diretamente de maneira positiva na sala de aula.

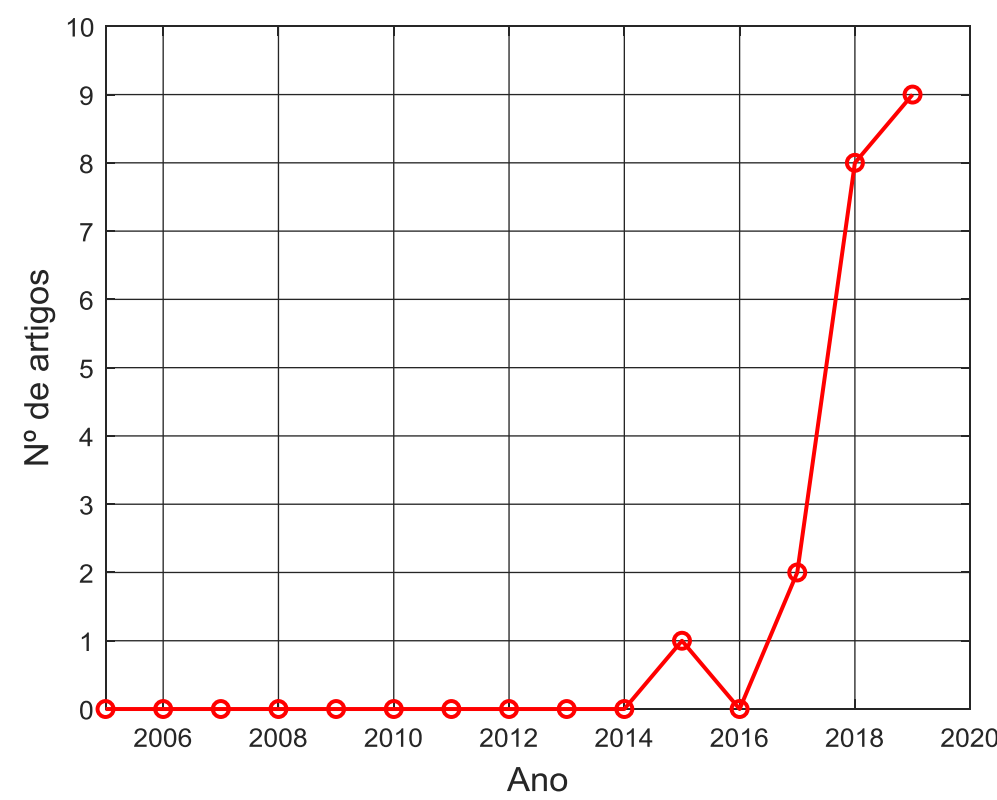

Fig. 4 - Publicação de artigos ao longo do período de 2005 a 2019. Fonte: elaborado pelos autores.

Dos 20 manuscritos selecionados, 3 são derivados de dissertações do MPECIM, 5 de dissertações do MNPEF e 12 de trabalhos de alunos da Licenciatura em Física, ou seja, 40\% originaram-se da produção da pós-graduação e $60 \%$ da graduação. O quadro 3 especifica os artigos pela identificação numérica (Id), mesma do quadro 1, quanto a origem da produção pelos cursos. 
Quadro 3 - Origem da produção dos artigos pelos cursos. Id é identificação numérica do trabalho. Fonte: elaborado pelos autores.

\begin{tabular}{|c|c|c|c|}
\hline Cursos & Licenciatura em Física & MPECIM & MNPEF \\
\hline Id & $1,2,6,8,9,10,12,14$, & 4,5 e 11. & $3,7,13,16$ e 18. \\
& $15,17,19$ e 20. & & \\
\hline
\end{tabular}

Em geral, os alunos de graduação que participaram na produção de artigos pertenciam ao PIBID, à Residência Pedagógica e à Extensão Universitária. Ainda que a produção de artigos seja menor por parte dos mestrandos - o que é compreensível, dado que estes em sua grande maioria são, também, docentes do ensino básico - pode-se ressaltar que, somente em 2019, os discentes do MNPEF publicaram nove resumos nos anais do I Encontro Regional do MNPEF Centro-Oeste/Norte (UnBNOTÍCIAS, 2019). Além disso, houve uma publicação de um livro sobre um produto educacional gerado pela produção de um aluno do MNPEF (HADAD; CASTANHEIRA, 2019). Entretanto, como já mencionado nos Passos Metodológicos, essas publicações não estão no escopo deste trabalho.

Uma avaliação indireta e condicionada da qualidade e impactos dos artigos foi feita utilizando o Qualis Periódicos Quadriênio 2013-2016 da Coordenação de Aperfeiçoamento de Pessoal de Nível Superior (CAPES), cujos dados estão expostos no Quadro 4. Os resultados apontaram que $60 \%$ das publicações têm estrato B1 e B2, superior a 50 pontos, comprovando que, de modo geral, os resultados foram satisfatórios. Vale destacar que os artigos abrangem diferentes escolas com distintas realidades, inclusive escolas da zona rural, mas apresentaram relevância real no cotidiano escolar, visto que realizam um trabalho necessário em regiões que carecem de materiais e alternativas metodológicas para o Ensino de Física. A partir da leitura dos artigos notou-se que resultados qualitativos importantes foram obtidos, tais como motivar estudantes da rede básica a ingressarem na licenciatura em Física e licenciandos em Física a ingressarem em mestrados profissionais e acadêmicos, como será visto na seção IV.5 (Formação Docente).

Quadro 4 - Classificação dos artigos selecionados segundo os estratos de qualidade do Qualis da Coordenação de Aperfeiçoamento de Pessoal de Nível Superior (CAPES) - quadriênio 2013-2016. Fonte: elaborado pelos autores.

\begin{tabular}{|c|c|c|c|c|c|c|c|c|c|}
\hline $\begin{array}{c}\text { Estratos do } \\
\text { Qualis } \\
\text { Periódicos }\end{array}$ & A1 & A2 & B1 & B2 & B3 & B4 & B5 & C & $\begin{array}{c}\text { Sem } \\
\text { classificação }\end{array}$ \\
\hline $\begin{array}{c}\text { Pontuação da } \\
\text { Área de } \\
\text { Ensino } \\
\text { (CAPES, } \\
\text { 2016) }\end{array}$ & 100 & 85 & 70 & 55 & 40 & 25 & 10 & 0 & 0 \\
\hline Quantidade & 0 & 0 & 10 & 2 & 4 & 1 & 0 & 0 & 3 \\
\hline
\end{tabular}


Os sujeitos da pesquisa dos estudos selecionados tinham faixa etária de 15 a 37 anos, distribuídos em diferentes instituições presentes nas cidades de Rio Branco (capital), Sena Madureira e Cruzeiro do Sul. O nível de escolaridade deles estava entre o $1^{\circ}$ e $3^{\circ}$ ano do Ensino Médio e $1^{\circ}$ e $8^{\circ}$ períodos de Licenciatura em Física.

\section{Descrição dos artigos selecionados}

Nesta parte será realizada uma breve descrição dos artigos escolhidos por área de natureza, seguindo as temáticas estabelecidas na Fig. 2. Os artigos serão designados pela mesma identificação numérica (Id) do quadro 1. Esta seção responde a primeira parte da pergunta "Quais as motivações e periodicidade das publicações em Ensino de Física no estado do Acre?” Essas motivações são expostas no início da descrição de cada trabalho.

\section{IV.1 Avaliação}

Nas avaliações externas, a depender de sua natureza, há uma tendência de se analisar os resultados numéricos sem considerar as associadas causas. Rezende e Osterman (2012) criticam essa atuação no caso especial das olimpíadas científicas, onde a literatura exposta pelas autoras foca somente nos resultados. Além disso, refletem e chamam atenção para a necessidade de considerar os contextos socioeconômicos e culturais ao analisar os dados de uma avaliação externa dessa natureza.

Sob esse referencial teórico, citado no parágrafo anterior, Melo Junior, Souza e Silva (2019), Id 9, analisam os resultados da Olimpíada Brasileira de Física das Escolas Públicas (OBFEP) nas edições de 2015 a 2018 do estado do Acre, com a motivação de compreender a relação dos resultados dos participantes da OBFEP no Acre com sua situação socioeconômica, e identificaram que os estudantes do interior do estado e residentes em locais de vulnerabilidade socioeconômica apresentam resultados inferiores quando comparados aos demais. Esse resultado está de acordo com o levantado por Rezende e Ostermann (2012). Também é proposta uma série de medidas para minimizar a discrepância do ensino entre essas regiões, municípios do interior e a região mais central da capital Rio Branco.

A avaliação no Ensino de Física tem seus desafios metodológicos, em especial quando se trata de avaliações externas. Para Werle (2010) e Heck (2018), avaliação externa é o processo de avaliar o ensino nas escolas púbicas e privadas, utilizando de ferramentas elaboradas por secretarias estaduais e órgãos nacionais de educação. De maneira geral, quando a avaliação é utilizada a favor da fomentação de uma educação edificante, esse instrumento tem grande potencial na aprendizagem, uma vez que a partir dele é possível diagnosticar falhas e acertos nos processos de ensino e aprendizagem, assim como projetar novas estratégias para suprir as necessidades e equívocos apontados na avaliação. Contudo, quando esse instrumento é utilizado de maneira equivocada, ou até mesmo de maneira 
punitiva, as avaliações se comportam como reprodutoras de desigualdades escolares (HECK, 2018; PERRENOUD, 1999).

\section{IV.2 Atividades Lúdicas}

As atividades de natureza lúdica têm sua parcela de importância no Ensino de Física e surgem nesse cenário, segundo Cardoso e Paraíso (2014), na tentativa de suprir a necessidade de uma mudança na postura tradicional do Ensino, de forma que essas atividades permitam a interação entre sujeitos, aguçando sua autonomia e criatividade. Os trabalhos enquadrados em atividades lúdicas utilizaram a gamificação (veja quadro 2); logo estão em concordância com o destacado por Cardoso e Paraíso (2014), uma vez que, como citado anteriormente, essa estratégia pode ser considerada uma metodologia ativa de ensino, como é o caso dos manuscritos analisados.

Com essa motivação, os artigos selecionados de Reis et al. (2018), Id 19, e Moreira et al. (2019), Id 10, buscam tratar das Leis de Newton, Energia e Termometria. As propostas dos artigos são uma alternativa, não somente às atividades mecânicas práticas no ensino de Física, mas também para motivar docentes, alunos do Ensino Médio e licenciandos a buscarem alternativas criativas para o ensino de Física. Como resultados, Reis et al. (2018) destacaram que os alunos ao final da atividade proposta estavam motivados, com menos dificuldades conceituais e matemáticas e houve uma contribuição no desenvolvimento cognitivo e raciocínio lógico dos participantes. Moreira et al. (2019) ressaltaram que seu trabalho incentivou uma maior participação dos estudantes nas aulas e que a interação mútua entre os alunos e com o professor contribui na evolução da aprendizagem.

Pereira, Fusinato e Neves (2009) apresentaram os jogos no Ensino como uma atividade lúdica, intelectual e afetiva, que favoreciam a aprendizagem, pois estimulavam e desenvolviam a interação social, bem como criavam um ambiente crítico e contextualizado, desprendendo-se da rotina mecânica das aulas expositivas. Com esse estímulo, os estudos de Araújo e Santos (2018), Id 2, Gomes, Carmo e Santos (2018), Id 6, e Amorim et al. (2018), Id 1, apresentaram propostas de jogos para aumentar a interação dos estudantes, motivar o desejo de aprendizagem, quebrar paradigmas da disciplina de Física e melhorar a aprendizagem.

Araújo e Santos (2018), Id 2, apresentaram um jogo dinâmico que favorecia a interação dos participantes, inicialmente voltado para alunos da graduação, e que poderia ser estendido a alunos do Ensino Médio. Os resultados mostraram que o jogo era eficiente em verificar os conhecimentos prévios, nivelar os estudantes e fomentar o pensamento crítico acerca de conceitos físicos básicos.

Gomes, Carmo e Santos (2018), Id 6, através da música intrigaram os alunos de uma escola estadual da zona rural e proporcionaram questionamentos deles sobre impulso e quantidade de movimento. Constataram, também, a partir do questionário e das observações 
feitas durante a atividade, que os estudantes conseguiram entender os conceitos e realizar novas indagações.

Amorim et al. (2018), Id 1, apresentaram uma sequência didática centrada em um jogo que facilitou a interação social entre professores, licenciandos bolsistas e alunos, permitindo que os últimos desenvolvessem o raciocínio lógico e cognitivo, lidassem com a timidez, coordenação motora e compreensão dos conceitos físicos envolvidos na atividade.

Moura, Melo Junior e Silva (2019), Id 11, motivados em conhecer os modelos mentais dos estudantes envolvidos, apresentaram um jogo para identificar esses modelos dos estudantes de uma Instituição Federal de Ensino, localizada no interior do Acre. Os autores auxiliaram também os estudantes a criarem modelos mentais para o conceito de movimento. Destacaram a importância de professores realizarem esse exercício para que possam reconhecer os próprios modelos mentais sobre os conceitos que ensinarão, de modo a contribuir melhor com o aprendizado dos alunos.

\section{IV.3 Tecnologias da Informação e Comunicação (TICs)}

Apesar do considerado tempo em que se discute o uso das TIC no Ensino, o seu emprego ainda é visto como uma barreira a ser superada. Essa, em geral, é associada à infraestrutura das instituições de ensino; contudo é necessária uma avaliação para saber se a formação dos docentes engloba esse tópico (SCHUHMACHER; ALVES FILHO; SCHUHMACHER, 2017; FERNANDES; RODRIGUES; FERREIRA, 2015).

Motivados na abordagem das TICs na formação docente, Hadad, Melo Junior e Silva (2018), Id 7, elaboraram uma sequência didática para o ensino de capacitância para licenciandos em Física na disciplina de Laboratório de Física Geral III, onde usaram simulações computacionais disponíveis no projeto PhET (Physics Education Technology Project) (PhET, 2020). Os objetivos eram inserir os discentes na prática de simulação e TIC motivando-os a utilizar essa ferramenta no ensino básico, discutir e avaliar a aprendizagem dos participantes sobre funcionamento de capacitor de placas paralelas e associação de capacitores. Ainda destacaram que esse tipo de atividade poderia contribuir para a permanência dos licenciandos no curso, dado que a maioria ingressa sem o intuito de atuar na docência e na área (COSTA; SANTOS, 2017). A preocupação inicial dos autores e a busca de alternativas para as problemáticas na formação docente e no uso das TIC não está isolada, sendo compartilhada pela comunidade internacional (TRAN et al., 2017; CHEN et al., 2019; LEE; LONGHURST; CAMPBELL, 2017).

Duarte e Nemer (2019), Id 4, utilizaram smartphones e a M-learning para expor materiais gráficos e simulações sobre diversos conteúdos de Física a alunos de uma escola de Ensino Médio. A M-learning é definida como a "didática que utiliza dispositivos móveis" (RIKALA, 2015). Com esses recursos, os autores conseguiram aumentar o interesse pela disciplina e melhoraram o entendimento de temas do eletromagnetismo. Contudo, vale destacar que esse trabalho não apresentou uma metodologia de pesquisa clara (Veja Quadro 2) 
e a coleta de dados concentrou-se totalmente na observação dos pesquisadores. A necessidade cada vez maior dessa abordagem, nessa modalidade de ensino também é uma preocupação no âmbito internacional (CHEN et al., 2019; BENNETT et al., 2019).

Rego, Silva e Peralta (2018), Id 18, partem da motivação de propiciar diversas sequências didáticas para o Ensino Médio utilizando TIC, acreditando no potencial dessas para o ensino e aprendizado de Física. O objetivo era traçar um paralelo entre o uso do livro didático e as atividades experimentais. As atividades foram testadas em sala de aula e obtiveram resultados positivos na aprendizagem dos estudantes. Essa prática de aliar TIC às atividades experimentais e trabalhá-las como parte de toda uma didática educacional é discutida e pesquisada por diversos autores em diferentes sistemas de ensino distribuídos pelo mundo (SOARES; REIS, 2019; BOZZO et al., 2019).

Motivados em proporcionar um contato com as TIC para alunos de uma região com pouco acesso à tecnologia e métodos não tradicionais de ensino, Santos et al. (2019), Id 15, utilizando o PhET (PhET, 2020) e o simulador Phyphox (PHYPHOX, 2020), compartilharam uma experiência didática realizada em uma escola da zona rural de um município do interior do Acre. A experiência permitiu que os estudantes aumentassem o interesse pelas aulas e conteúdos, quando comparado ao aprendizado pelo método tradicional.

Esteves e Silva (2019), Id 5, impulsionados pelo interesse em saber o que havia de ferramentas disponíveis para o uso de TIC no ensino de Física, em uma revisão bibliográfica analisaram a eficácia do uso das TIC para o ensino de Física e observaram que há diversas plataformas e mídias voltadas para a temática e que é possível o uso de simulações, jogos e vídeos no ensino de Física com o objetivo de melhorar a aprendizagem e contribuir para o desenvolvimento cognitivo dos alunos.

\section{IV.4 Atividade Experimental}

As atividades experimentais no Ensino de Física são bastante utilizadas no processo de ensino aprendizagem na esfera nacional e internacional (PEDERSEN et al., 2020; RAMOS et al., 2020; GONÇALVES; ARAUJO; RODRIGUES, 2020). Essas atividades podem exercer, ou não, um importante papel no desenvolvimento do conhecimento científico dos estudantes. Pesquisas utilizando o laboratório remoto têm surgido na literatura (OLIVEIRA et al. 2020; BARROS; DIAS, 2019), podendo ser associadas às TIC e à formação docente. Ao pensar em uma aula diferente da expositiva tradicional, uma das primeiras alternativas que pode ser cogitada pelo docente é a atividade experimental; essas atividades poderão ter um importante papel e significativo potencial, desde que sejam planejadas e executadas priorizando a autonomia dos alunos e o processo (caminho) em vez de o resultado (chegada) (BORGES, 2002).

Oliveira et al. (2015), Id 12, incentivados em fomentar o laboratório didático e atividades experimentais na modalidade de Educação de Jovens e Adultos (EJA) do Acre, apresentaram rotinas de ensino voltadas a essa modalidade e contribuíram para $\mathrm{o}$ 
enriquecimento de materiais didáticos utilizados no EJA, tendo em vista a escassez desses materiais e dessas abordagens naquele período.

Melo Junior e Silva (2017), Id 8, motivados em reduzir as dificuldades dos estudantes de uma escola estadual de Ensino Médio em compreender os conceitos dos processos de eletrização, elaboraram uma atividade didática com os objetivos de melhorar esse cenário e verificar o aprendizado de estudantes em vulnerabilidade socioeconômica. Os resultados mostraram que a metodologia escolhida de fomentar os estudantes para que eles obtivessem, por conta própria, as respostas para perguntas feitas foi satisfatória. Além do mais, os estudantes em vulnerabilidade apresentaram um rendimento muito bom na atividade e no decorrer do ano letivo.

Incitados em saber os efeitos do uso de mnemônicos simultaneamente com atividades experimentais, Santos, Gomes e Souza (2018), Id 14, relataram uma experiência de uma sequência didática sobre associação de resistores, que faz uso de atividades experimentais de baixo custo, juntamente a mnemônicos, para turmas do $3^{\circ}$ ano do Ensino Médio de uma escola localizada em Rio Branco, Acre. Os autores concluíram que com o uso de mnemônicos os estudantes assimilaram melhor os conceitos trabalhados: associação de resistores, resistência e circuitos.

\section{IV.5 Formação Docente}

A formação de professores é um tema complexo por natureza, a constante mudança social e o advento da tecnologia entrelaçam-se diretamente com a formação e a prática docente. Inevitavelmente a formação de professores de Física é um tema igualmente complicado e ocupa um grande espaço nas publicações em periódicos nacionais em Ensino de Ciências. Formar professores de Física passa a ser relevante a partir de 1931, quando essa disciplina é implementada no ensino secundário ou, como denominado atualmente, Ensino Médio (CALADO; ROSA, 2019).

No estado do Acre, a formação de professores de Física passou a ser recentemente investigada, inicialmente com o trabalho de Costa e Santos (2017), Id 3, incitadas a levantar os conteúdos estudados pelos ingressantes na licenciatura durante o Ensino Médio e a motivação para ingressar no curso. As autoras apontaram que os temas que abrangem a Física Moderna não foram estudados pelos participantes da pesquisa; também foi constatado que, em relação aos conteúdos lecionados (Física Clássica), houve alguns que foram mais trabalhados. Outro destaque era o fato de que a retenção em algumas disciplinas poderia estar ligada à mudança da metodologia, utilizada no Ensino Médio, para a empregada na graduação. Na última, é necessário desenvolver o pensamento, assim a prática de decorar fórmulas tornou-se obsoleta e ineficiente. As autoras perceberam que poucos ingressantes têm interesse na docência e uma parte desses ingressou no curso com a intenção de migrar para outras graduações. 
Santos et al. (2018), Id 16, incitados em avaliar as contribuições do PIBID na formação dos discentes da licenciatura, observaram um aumento no desejo à docência e o reconhecimento do PIBID como importante programa no processo de contato do licenciando com a escola, proporcionando experiências plurais.

Souza, Santos e Ghidini (2019), Id 17, motivados em avaliar a experiência obtida pelos participantes da extensão universitária, apresentam como se deu esse processo. Em linhas gerais, os licenciandos preparam minicursos para professores da rede básica de ensino; o objetivo era de promover a troca de experiências entre os docentes da licenciatura, os da rede básica e os docentes em formação. Esse trabalho proporcionou a elaboração de novos recursos pedagógicos e metodológicos por parte dos discentes e promoveu o contato com a pesquisa científica, rendendo trabalhos apresentados no VIII Encontro de Física de Rondônia em Porto Velho - Rondônia (UNIR, 2019).

Incitados em saber a opinião dos discentes da licenciatura em Física da UFAC sobre o curso, Rocha, Santos e Pinheiro (2019), Id 20, analisaram a partir de questionários as percepções dos licenciandos. Eles observaram que os discentes, apesar de satisfeitos com o curso, careciam de mais materiais e recursos para aulas de laboratório, interessavam-se pela pesquisa científica e, também, por ingressar em um mestrado e doutorado.

Santos, Pinheiro e Rocha (2019), Id 13, incentivados em avaliar o impacto do I Congresso de Física no Acre (UFAC, 2018), realizado na Universidade Federal do Acre, constataram que o evento contribuiu na formação docente, uma vez que mobilizou os licenciandos e pós-graduandos e motivou a produção científica.

A preocupação dos docentes da licenciatura em Física da UFAC, a busca por alternativas ao ensino tradicional, a melhoria da capacitação desses profissionais e publicação do cenário local e das soluções estudas, mostra que os docentes envolvidos e os artigos selecionados estão em convergência com as pesquisas nacionais e internacionais (der GRAAF et al. 2019; BENNETT et al., 2019; WU; HU; WANG, 2019), sobretudo na formação de professores de STEM (Science, Technology, Engnieering and Mathematics) para atuarem nos diferentes níveis da educação.

\section{Considerações finais}

No Acre, não houve publicação em Ensino de Física antes da implementação do MPECIM em 2014, entretanto, as primeiras publicações surgiram de agentes ligados à licenciatura (professores e alunos). Com o surgimento dos programas de pós-graduação (MPECIM e MNPEF), a produção tornou-se, cada vez mais, elemento do cotidiano que envolve os docentes e discentes da licenciatura e pós-graduação.

Dessa recente trajetória local de pesquisa na área, foi evidenciado que atividades lúdicas são a temática mais pesquisada, com 30\% dos trabalhos publicados, seguida por formação docente e TIC, ambas com $25 \%$, atividades experimentais, com $15 \%$ e avaliação, com 5\%. Desses trabalhos, $40 \%$ estão ligados a mestrandos dos dois programas existentes na 
instituição MNPEF e MPECIM, enquanto 60\% estão ligados a discentes da graduação participantes do PIBID, Residência Pedagógica e Extensão Universitária, o que evidencia o importante papel da UFAC no ensino, pesquisa e extensão.

Uma constatação preocupante é o fato de grande parte dos trabalhos não utilizarem um referencial teórico na análise dos dados, o que indica uma lacuna nesses trabalhos. Essa constatação abre caminhos para questionamentos sobre a qualidade dos trabalhos e o porquê da não utilização de referenciais teóricos nessas análises, ficando somente com a interpretação de dados feita pelos autores, sem embasar suas declarações ou apresentarem pontos discordantes, ou seja, sem enriquecer a discussão e os resultados obtidos.

Os investimentos na formação docente da licenciatura em Física da UFAC proporcionaram uma mudança de pensamento do licenciando, passando de um desejo de migrar para outros cursos e o desinteresse pela docência, (COSTA; SANTOS, 2017), Id 3, para o desejo de melhorias nos insumos de laboratório e o interesse em ingressar em uma pósgraduação (mestrado e doutorado), (ROCHA; SANTOS; PINHEIRO, 2019), Id 13. Além disso, esses investimentos devem ser continuados e intensificados, visto que fica claro que esses programas (PIBID, Residência Pedagógica, MPECIM e MNPEF) contribuíram de maneira positiva para o aumento da produção científica em Ensino de Física no Acre (Fig. 4); além de motivar reflexões, acerca da formação docente, esses programas também tiveram um impacto na atitude dos docentes e discentes da licenciatura de modo que os impactos positivos poderão ser sentidos diretamente na sala de aula.

Além disso, notamos que os programas exerceram uma mudança fundamental de atitude em relação a sua própria formação e divulgação dos resultados da sua pesquisa. Destaca-se que os programas propiciaram aos alunos um estudo sobre sua própria formação, com $25 \%$ de todos os artigos analisados sendo da temática formação docente.

Os trabalhos ligados aos mestrados profissionais apresentaram resultados de uma ótica de profissionais que já atuaram na área e que eventualmente realizaram uma pesquisa mais profunda sobre a temática, dada a exigência acadêmica da produção da dissertação e de um produto educacional.

Contudo, a produção realizada por discentes da graduação teve grande importância, pois desenvolveu o pensamento e prática científica nos pesquisadores e permitiu o contato com a prática docente. Os trabalhos foram realizados em localidades quase nunca atingidas por esses projetos, proporcionando experiências distintas das usualmente realizadas. Além disso, os programas colaboraram positivamente para produção científica no estado e estimularam os licenciandos a iniciar a pesquisa.

Dessa forma, a preocupação dos docentes da licenciatura e dos mestrados profissionais, refletida nas recentes publicações e motivação dos licenciandos, sinalizou caminhos de inovação de materiais e métodos do ensino, o que deve alavancar o nível de aprendizado em Física no Estado. Além disso, as futuras gerações de professores da área 
sairão da graduação com uma experiência muito maior em pesquisa e com a formação mais diversificada.

As publicações científicas são consequências das pesquisas científicas e essas devem ser motivadas pelo desejo de descoberta, aprimoramento ou mudança de uma ideia, método ou teoria. Sendo assim, para seguir formando profissionais capacitados para as diferentes realidades educacionais presentes no Estado, é necessário buscar um nivelamento e um ensino emancipatório. O investimento nas universidades públicas da Região Norte é essencial para reduzir a discrepância dos níveis de excelência com as universidades públicas do sudeste e sul do país.

\section{Agradecimento}

Os autores agradecem ao CNPq, à CAPES, à UFAC, ao MNPEF (polo-59) e ao MPECIM.

\section{Referências bibliográficas}

ALBUQUERQUE, E. M et al. Produção científica e tecnológica das regiões metropolitanas brasileiras. Revista de Economia Contemporânea, v. 9, n. 3, p. 615-642, set./dez, 2005.

ALBUQUERQUE, E. M et al. A Distribuição Espacial da Produção Científica e Tecnológica Brasileira: uma Descrição de Estatísticas de Produção Local de Patentes e Artigos Científicos. Revista Brasileira de Inovação, v. 1, n. 2, p. 225-251, jul./dez. 2009.

AMORIM, A. M. A. et al. Jogo de mímica para o ensino de propagação do calor: condução, convecção e irradiação. Revista Prática Docente, v. 3, n. 1, p. 158-170, jan./jun. 2018.

ARAÚJO, E. S.; SANTOS, B. M. Jogo das grandezas: um recurso para o ensino de física. Revista do Professor de Física, v. 2, n. 2, p. 73-83, 2018.

BARROS, T. R.; DIAS, W. S. Práticas experimentais de Física a distância: Desenvolvimento de uma aplicação com Arduino para a realização do Experimento de Millikan remotamente. Revista Brasileira de Ensino de Física, v. 41, n. 4, p. e20190049.1- e20190049.8, 2019.

BENNETT, J. et al. Mixed methods, mixed outcomes? Combining a RCT and case studies to research the impact of a training programme for primary school Science teachers. International Journal of Science Education, v. 41, n. 4, p. 490-509, 2019.

BORGES, A. T. Novos rumos para o laboratório escolar de ciências. Caderno Brasileiro de Ensino de Física, v. 19, n. 3, p. 291-313, jan. 2002. 
BOZZO, G. et al. Imaging and studying standing waves with a homemade Melde-type apparatus and information and communication technology (ICT). The Physics Teacher, v. 57, n. 9, p. 612-615, 2019.

BRASIL. Ministério da Ciência, Tecnologia, Inovações e Comunicações. Portaria no . 1.122, de 19/03/2020. Define as prioridades, no âmbito do Ministério da Ciência, Tecnologia, Inovações e Comunicações (MCTIC), no que se refere a projetos de pesquisa, de desenvolvimento de tecnologias e inovações, para o período 2020 a 2023. Brasília: 2020a. Disponível em: <http://www.in.gov.br/en/web/dou/-/portaria-n-1.122-de-19-de-marco-de2020-249437397>. Acesso em: 05 mai. 2020.

BRASIL. Ministério da Educação. Portaria no. 34, de 09/03/2020. Dispõe sobre as condições para fomento a cursos de pós-graduação stricto sensu pela Diretoria de Programas e Bolsas no País da CAPES. Brasília: 2020b. Disponível em: <http://www.in.gov.br/web/dou/-/portaria-n34-de-9-de-marco-de-2020-248560278>. Acesso em: 05 mai. 2020.

CALADO, H. C.; ROSA, M. I. P. Formação de professores de Física e interdisciplinaridade: episódios de refração de políticas em narrativas de reforma curricular. Ciência \& Educação, v. 25, n. 2, p. 523-538, 2019.

CAPES. Critérios de Classificação Qualis - Ensino. 2016. Disponível em:

$<$ https://www.gov.br/capes/pt-br/centrais-de-conteudo/documentos/avaliacao/arquivo_qualis. pdf>. Acesso em: 24 mai. 2020.

CAPES. Programa Institucional de Bolsa de Iniciação à Docência - PIBID. CAPES, 2018a. Disponível em: <http://www.capes.gov.br/educacao-basica/capespibid>. Acesso em: 05 mai. 2020.

CAPES. Programa de Residência Pedagógica. CAPES, 2018b. Disponível em: $<$ http://www.capes.gov.br/educacao-basica/programa-residencia-pedagogica>. Acesso em: 05 mai. 2020.

CARDOSO, L. R.; PARAÍSO, M. A. Álbum fotográfico: um mapa de cenários discursivos na produção acadêmica brasileira sobre aulas experimentais de ciências. Ciência \& Educação, v. 20, n. 1, p. 83-115, 2014.

CHEN, M. et al. How to promote Chinese primary and secondary school teachers to use ICT to develop high-quality teaching activities. Educational Technology Research and Development, v. 67, n. 6, p. 1593-1611, 2019. 
COSTA, S. S.; SANTOS, B. M. Tópicos de física estudados no Ensino Médio por ingressantes no curso de licenciatura em física. South American Journal of Basic Education, Technical and Technological, v. 4, n. 2, p. 202-210, 2017.

der GRAAF, J. et al. A combined approach to strengthen children's scientific thinking: direct instruction on scientific reasoning and training of teacher's verbal support. International Journal of Science Education, v. 41, n. 9, p. 1119-1138, 2019.

DESSBESEL, R. S.; SILVA, S. C. R; SHIMAZAKI, E. M. O processo de ensino e aprendizagem de Matemática para alunos surdos: uma revisão sistemática. Ciência \& Educação, v. 24, n. 2, p. 481-500, 2018.

DUARTE, A. F.; NEMER, K. L. V. B. Aprendizagem móvel da Física: uma experiência didática sobre eletromagnetismo no Ensino Médio da rede pública no Estado do Acre. Revista do Professor de Física, v. 3, n. 2, p. 34-49, 2019.

ENPEC. XI ENPEC Florianópolis - SC. Florianópolis: 2017. Disponível em: $<$ http://www.abrapecnet.org.br/enpec/xi-enpec/>. Acesso em: 21 mai. 2020.

ESTEVES, W. A.; SILVA, M. C. South American Journal of Basic Education, Technical and Technological, 2019.

FERNANDES, G. W. R.; RODRIGUES, A. M.; FERREIRA, C. A. Módulos temáticos virtuais: uma proposta pedagógica para o ensino de ciências e o uso das TICs. Caderno Brasileiro de Ensino de Física, v. 32, n. 3, p. 934-962, 2015.

GALVÃO, C. M.; SAWADA, N. O.; TREVIZAN, M. A. Revisão sistemática: recurso que proporciona a incorporação das evidências na prática da enfermagem. Revista LatinoAmericana de Enfermagem, v. 12, n. 13, p. 549-556, mai/jun 2004.

GIL, A. C. Como elaborar projetos de pesquisa. 4. ed. São Paulo: Atlas, 2002.

GOMES, B. G.; CARMO, G. L.; SANTOS, B. M. Música como recurso didático para o ensino de impulso e quantidade de movimento. South American Journal of Basic Education, Technical and Technological, v. 5, n. 2, p. 215-224, 2018.

GONÇALVES, M. H.; ARAUJO, L. E. E.; RODRIGUES, V. Lentes de gelatina. Revista Brasileira de Ensino de Física, v. 42, n. 11, p. e20190095.2 - e20190095.6, 2020. 
HADAD, I. H.; CASTANHEIRA, M. Bobina de Tesla de estado sólido aplicada no ensino de Física. 1. ed. Riga: Novas Edições Acadêmicas, 2019.

HADAD, I. H.; MELO JUNIOR, E. B. M; SILVA, M. C. Simulação computacional no ensino de capacitância para cursos de graduação. Caderno de Física da UEFS, v. 16, n. 1, p. 1202.1-16, 2018.

HECK, M. F. Sistema Nacional de Avaliação da Educação Básica (SAEB): compreendendo a realidade educacional. Revista Eletrônica Científica Ensino Interdisciplinar, v. 4, n. 11, p. 410-422, 2018.

LEE, H.; LONGHURST, M.; CAMPBELL. T. Teacher learning in technology professional development and its impact on student achievement in Science. International Journal of Science Education, v. 39, n. 10, p. 1282-1303, 2017.

LIBÂNEO, J. C. Didática. 1. ed. Cortez, 1994.

MELO JUNIOR, E. B. M; SILVA, M. C. Ensino dos processos de eletrização no $3^{\circ}$ ano do Ensino Médio usando as teorias cognitivistas de Vygotsky e de Ausubel aliadas a atividades experimentais. South American Journal of Basic Education, Technical and Technological, v. 4, n. 2, p. 167-201, 2017.

MELO JUNIOR, E. B. M.; SOUZA, C. A. L; SILVA, M. C. A olimpíada brasileira de física das escolas públicas no Acre: resultados e influência da vulnerabilidade socioeconômica. REAMEC - Rede Amazônica de Educação em Ciências e Matemática, v. 7, n. 3, p. 152$175,2019$.

MOREIRA, B. W. S. et al. O Jogo da Velha sobre Mecânica: Relato de Experiência. Destaques Acadêmicos, v. 11, n. 4, p. 18-35, 2019.

MOURA, G. T. M.; MELO JUNIOR, E. B. M.; SILVA, M. C. Modelos mentais de conceitos de movimento por estudantes do primeiro ano do Ensino Médio. South American Journal of Basic Education, Technical and Technological, v. 6, n. 2, p. 123-148, 2019.

OLIVEIRA, A. G. et al. Uso de experimentos de física em turmas de educação de jovens e adultos. Caderno de Física da UEFS, v. 13, n. 2, p. 2202.1-13, 2015.

OLIVEIRA, I. et al. Estudo das propriedades do Diodo Emissor de Luz (LED) para a determinação da constante de Planck numa maquete automatizada com o auxílio da 
plataforma Arduíno. Revista Brasileira de Ensino de Física, v. 42, n. 09, p. e20190105.1e20190105.9, 2020.

PEDERSEN, H. et al. An experimental system for studying the plane pendulum in physics laboratory teaching. European Journal of Physics, v. 41, n. 1, p. 1-23, 2020.

PEREIRA, R. F.; FUSINATO, P. A.; NEVES, M. C. D. Desenvolvendo um jogo de tabuleiro para o ensino de física. In: ENCONTRO NACIONAL DE PESQUISA EM EDUCAÇÃO EM CIÊNCIAS, VII, 2009. Anais...

PEREIRA, T. Z. M.; SILVEIRA, C. A produção acadêmica da região norte: uma análise na ata do xi encontro nacional de pesquisa em educação em ciências. REAMEC - Rede Amazônica de Educação em Ciências e Matemática, v. 7, n. 2, p. 2445-260, jul./dez 2019.

PERRENOUD, P. Avaliação: da excelência à regulação das aprendizagens - entre duas lógicas. Porto Alegre: Artes Médicas Sul, 1999.

PhET, Interactive Simulations. Simulações Interativas de Ciências e Matemática. 2020. Disponível em: $<$ https://phet.colorado.edu/pt_BR/>. Acesso em: 24 mai. 2020.

PHYPHOX, Physical Phone Experiments. Your smartphone is a mobile lab. Disponível em: $<$ https://phyphox.org/>. Acesso em: 24 mai. 2020.

RAMOS, L. et al. An experiment to observe Stevin's law with an Arduino. Physics Education, v. 55, p. 1-4, 2020.

REGO, W. R. S.; SILVA, M. C.; PERALTA, M. J. A. South American Journal of Basic Education, Technical and Technological, v. 5, n. 2, p. 167-183, 2018.

REIS, J. S. et al. Ensino de Termologia com aplicação do jogo "Caminhos Termométricos". Física na Escola, v. 16, n. 2, p. 57-61, 2018.

REZENDE, F.; OSTERMANN, F. Olimpíadas de ciências: uma prática em questão. Ciência \& Educação, v. 18, n. 1, p. 245-256, 2012.

RIKALA, J. Designing a Mobile Learning Framework for a Formal Educational Context. 2015. 241 f. Dissertação (Mestrado) - University of Jyväskylä, Faculty of Information Technology, Jyväskylä. 
ROCHA, Y. G. M.; SANTOS, B. M.; PINHEIRO, A. R. C. Percepções dos Alunos de Física da Ufac sobre o curso. Debates em Educação, v. 11, n. 25, p. 107-122, set./dez, 2019.

SAMPAIO, R. F.; MANCINI, M. C. Estudos de revisão sistemática: um guia para síntese criteriosa da evidência científica. Brazilian Journal of Physical Therapy, v. 11, n. 1, p. 8389, jan./fev 2007.

SANTOS, B. M.; PINHEIRO, A. R. C.; ROCHA, Y. G. M. Contribuições E Limitações Sobre A Realização Do I Congresso De Física Do Acre. South American Journal of Basic Education, Technical and Technological, v. 6, n. 2, p. 40-54, 2019.

SANTOS, B. M.; GOMES, M. R. S.; SOUZA, G. L. C. Relato de experiência: o uso de experimentos e mnemônicos no ensino de circuitos elétricos para alunos da zona rural. Educação Básica Revista, v. 4, n. 2, p. 311-320, 2018.

SANTOS, B. M. et al. Formação Inicial de Professores de Física na UFAC: As Contribuições e Limitações do PIBID. South American Journal of Basic Education, Technical and Technological, v. 5, n. 2, p. 201-214, 2018.

SANTOS, G. et al. Sequência de ensino investigativa para o ensino da lei de Hooke e movimento harmônico simples: uso do aplicativo Phyphox, o simulador Phet e GIF's. Revista de Enseñanza de la Física, v. 31, n. 2, p. 97-108, 2019.

SCHUHMACHER, V. R. N.; FILHO, J. P. A.; SCHUHMACHER, E. As barreiras da prática docente no uso das tecnologias de informação e comunicação. Ciência \& Educação, v. 23, n. 3, p. 563-576, 2017.

SIDONE, O. J. G; HADDAD, E. D.; MENA-CHALCO, J. P. A ciência nas regiões brasileiras: evolução da produção e das redes de colaboração científica. TransInformação, v. 28, n. 1, p. 15-31, jan./abr, 2016.

SILVA, J. B; SALES, G L; CASTRO, J B. Gamificação como estratégia de aprendizagem ativa no ensino de Física. Revista Brasileira de Ensino de Física, v. 41, n. 4, p. e20180309, 2019.

SILVEIRA, D. T.; CÓRDOVA, F. P. Pesquisa Científica. In: GERHART, T. E.; SILVEIRA, D. T. Métodos de pesquisa. 1. ed. Porto Alegre: Editora da UFRGS, 2009. p. 31-43. 
SOARES, A. A.; REIS, T. O. Studying Faraday's law of induction with a smartphone and personal computer. Physics Education, v. 54, p. 1-7, 2019.

SOUZA, G. A. P.; SANTOS, B. M.; GHIDINI, A. C. Experiências da extensão universitária na formação de professores de ciências. Scientia Naturalis, v. 1, n. 5, p. 130-139, 2019.

TRAN, T.-B. et al. Learning to teach inquiry with ICT. Physics Education, v. 53, n. 1, p. 015003, 2017.

UFAC. I Congresso de Física no Acre - Pesquisas Físicas na Amazônia Ocidental. 2018. Disponível em: <http://www.ufac.br/site/eventos/i-congresso-de-fisica-do-acre>. Acesso em: 24 mai. 2020.

UnBNOTÍCIAS. I Encontro Regional do Centro-Oeste/Norte MNPEF. Brasília: 2019. Disponível em: <https://www.noticias.unb.br/component/agenda/agenda/2565> . Acesso em: 22 mai. 2020.

UNIR. VIII Encontro de Física de Rondônia. Rondônia: 2019. Disponível em: $<$ http://www.fisicajp2.unir.br/evento/exibir/729>. Acesso em: 25 mai. 2020.

USP. 15 universidades públicas produzem $60 \%$ da ciência brasileira. Jornal da USP, 2019. Disponível em: $<$ https://jornal.usp.br/universidade/politicas-cientificas/15-universidadespublicas-produzem-60-da-ciencia-brasileira/>. Acesso em: 05 mai. 2020.

WERLE, F. O. C. (Org.). Avaliação em larga escala: foco na escola. São Leopoldo: Oikos; Brasília: Liber Livro, 2010.

WU, B; HU, Y.; WANG, M. Scaffolding design thinking in online STEM preservice teacher training. British Journal of Educational Technology, v. 50, n. 5, p. 2271-2287, 2019.

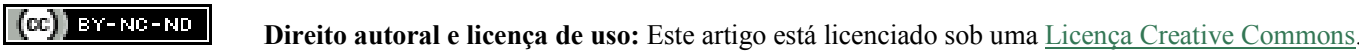

